\title{
2-D integrated numerical modeling for the potential of solitary wave-induced residual liquefaction over a sloping porous seabed
}

\author{
Hongyi Zhao ${ }^{1}$ • Dong-Sheng Jeng ${ }^{1}\left([) \cdot\right.$ Huijie Zhang ${ }^{2}$ • \\ Jisheng Zhang ${ }^{3}$. Hong Zhang ${ }^{1}$
}

Received: 20 December 2014 / Accepted: 27 July 2015 / Published online: 20 August 2015

(C) Springer International Publishing AG 2015

\begin{abstract}
A 2-D integrated numerical model is developed for liquefaction due to the build-up of pore pressure in porous sloping seabed subject to solitary wave loading. In the integrated 2-D model, the propagation of a solitary wave over a porous sloping seabed is governed using the volumeaveraged Reynolds averaged Navier-Stokes equations, in which discontinuity of the flow (i.e., wave breaking due to shoaling, hydraulic jump during the wave drawdown phase) can be captured with $k-\epsilon$ model, while Biot's consolidation equations are used for linking the solid-pore fluid interaction. Regarding the wave-induced residual soil response, a new 2-D pore pressure build-up model is developed with the new definition of the source term where the phase-resolved oscillatory shear stress is involved. The initial consolidation state of the sloping seabed foundation is considered under hydrostatic load using theory of poro-elasticity. The numerical results indicate that compared to a 1:6 slope, the
\end{abstract}

Dong-Sheng Jeng

d.jeng@griffith.edu.au

Hongyi Zhao

hongyi.zhao@griffithuni.edu.au

Huijie Zhang

frank071@163.com

Jisheng Zhang

jszhang@hhu.edu.cn

Hong Zhang

hong.zhang@griffith.edu.au

1 Griffith School of Engineering, Griffith University Gold Coast Campus, Southport, QLD 4222, Australia

2 Faculty of Civil Engineering and Mechanics, Jiangsu University, Zhenjiang 212013, China

3 State Key Laboratory of Hydrology-Water Resources and Hydraulic Engineering, Hohai University, Nanjing 210098, China wave-breaking process is more likely to occur in the case of a mild 1:15 slope due to wave shoaling and that a mild 1:15 slope experiences a longer duration of the wave run-up and drawdown compared to that in a steep 1:6 slope. Furthermore, the results suggest that the potential for liquefaction first occurs near the intersection between the initial shore line and the bed boundary. Then it will be extended both laterally and vertically to the neighboring points. The depth of the liquefaction zone increases and the width of the liquefaction zone decreases as the bed slope increases. Parametric studies indicate that the build-up of residual pore pressure can accumulate to a large value in the case of soil with lower permeability and lower relative density under larger wave loading.

Keywords Solitary wave - Pre-consolidation - Wavesloping seabed interaction - Residual liquefaction · VARANS equation · Biot's theory

\section{Introduction}

Tsunami with huge amount of energy and fast traveling speed causes catastrophic losses for the properties around coastlines. Besides widespread destruction and erosion to coastal infrastructures, tsunami also causes serious damages to the supporting structural foundations and roadways in the form of liquefaction due to an instantaneous increase in build-up of excess pore pressure with accompanying decreases in vertical effective stress in the area where tsunami could reach. Once the soil is liquefied, it will behave like a heavy fluid without any shear resistance resulting in collapse or tilting of structures. Therefore, it is important for coastal and geotechnical engineers to accurately evaluate the seabed stability under the tsunami waves involved in the design of marine structures. 
Two mechanisms were identified in previous laboratory experiments and field measurements (Zen and Yamazaki 1990; Nago et al. 1993): (i) transient or momentary liquefaction and (ii) residual liquefaction. The transient liquefaction normally occurs within unsaturated marine soils under wave troughs and appears as periodic responses to ocean waves. The residual liquefaction normally occurs in a fully saturated seabed due to the build-up of excess pore pressure caused by the cumulative contraction of the soil under the action of cyclic shearing. In this study, the residual liquefaction is considered.

Based on Biot's poro-elastic theory (Biot 1941), waveinduced pore pressure and effective stress in an elastic porous medium have been widely investigated through analytical approximations or numerical modeling in the past few decades (Madsen 1978; Hsu and Jeng 1994; Zhang and Jeng 2005; Jeng and Zhang 2005; Ulker et al. 2009; Jeng et al. 2013; Ye et al. 2014). However, most previous investigations have only examined the soil response in a flat seabed foundation under regular wave loading. Studies regarding the interaction between tsunami waves and sloping seabed foundations are relatively rare, mainly through laboratory tests and numerical modeling due to the difficulties in obtaining real-time data on site (Sumer et al. 2011; Young et al. 2009; Xiao et al. 2010). Among available investigations, Sumer et al. (2011) conducted a series of experimental studies for the measurement of surface elevation of breaking solitary wave over a sloping foundation, as well as the wave-induced pore pressures, bed stresses, and its fluctuation. Young et al. (2009) numerically investigated the transient soil response in a coastal slope under solitary wave loading. Based on this framework, Xiao et al. (2010) further investigated maximum liquefaction depth in a sloping seabed foundation under the action of breaking solitary waves through detailed parametric studies. In both studies, liquefaction occurred in the location near the bed surface where upward vertical pore pressure gradients were observed during the drawdown phase. Most recently, Ye et al. (2013) developed an integrated numerical model to investigate the stability of seabed foundation supporting breakwater under solitary wave loading. However, all the aforementioned investigations were limited to oscillatory mechanism, rather than residual mechanism.

One of the leading studies for wave-induced residual mechanism was given by Seed and Rahman (1978). It was reported that cyclic shear stress in the soil induced by dynamic wave loading which varies harmonically in space and time can cause the contraction of relatively loose soils and lead to an increase in the mean excess pore water pressure, if drainage is impeded. Based on this framework, numerous studies for the wave-induced residual liquefaction in marine sediments have been carried out (McDougal et al. 1989; Sumer and Fredsøe 2002; Jeng 2013; Sumer 2014).
All these were limited to 1-D models, in which the waveinduced shear stress amplitude over wave period was used as a source for the generation of pore pressure. Recently, this 1-D model has been extended into 2-D situation with the new definition of source term, in which the phaseresolved shear stress is involved (Jeng and Zhao 2014). This 2-D framework was further applied to more general situation with submarine pipeline embedded in the seabed (Zhao et al. 2014) and breakwater sitting on the seabed (Zhao and Jeng 2015). Another approach for the wave-induced residual soil response is poro-elasto-plastic model. Among these, Sekiguchi et al. (1995) proposed a 1-D model for a shallow soil layer under standing waves. The importance of cyclic plasticity in wave-soil interactions has been emphasized through the application of centrifuge wave tests carried out by Sassa and Sekiguchi (1999). Considering the rotations of principal stress axes, Sassa and Sekiguchi (2001) developed a 2-D elasto-plastic constitutive model to describe the behavior of sands under cyclic loading. However, all these have been only concerned with the case in which flat seabed foundation under progressive waves or standing waves were involved. To the best knowledge of the authors, no literature is available on investigation of the pore pressure build up and evaluation of potential for residual liquefaction in a coastal slope foundation subject to solitary wave run-up and drawdown.

In this study, with the new definition of the source term (phase-resolved instant shear stress), a 2-D integrated model will be developed to investigate the sloping seabed response under solitary wave loading, involving both the oscillatory mechanisms and residual mechanisms. Firstly, laboratory experiments and analytical solutions are used to support the present integrated 2-D numerical model. Second, the wave profiles during the run-up and drawdown, as well as the waveinduced seabed response for the two different slopes, will be investigated and compared. Finally, the effects of wave characteristics and soil properties on the wave-induced pore pressure accumulation and the maximum liquefaction depth will be carried out through parametric studies.

\section{Theoretical model}

In this study, we consider the phenomenon of solitary waves with various initial height $(H)$ over water depth $d=10 \mathrm{~m}$ propagating over a porous sloping seabed, as depicted in Fig. 1. The toe of the beach is located at $x=50 \mathrm{~m}$, and wave is centered at $x=400 \mathrm{~m}$ at $t=0 \mathrm{~s}$. The slopes of the seabed are selected to be 1:6 and 1:15 to represent a mild slope and a steep slope beach, respectively. The depth of sand layer below the slope is assumed to be $20 \mathrm{~m}$. The properties of sand are given in Table 1. 
Fig. 1 Sketch of solitary wave and sloping seabed interactions

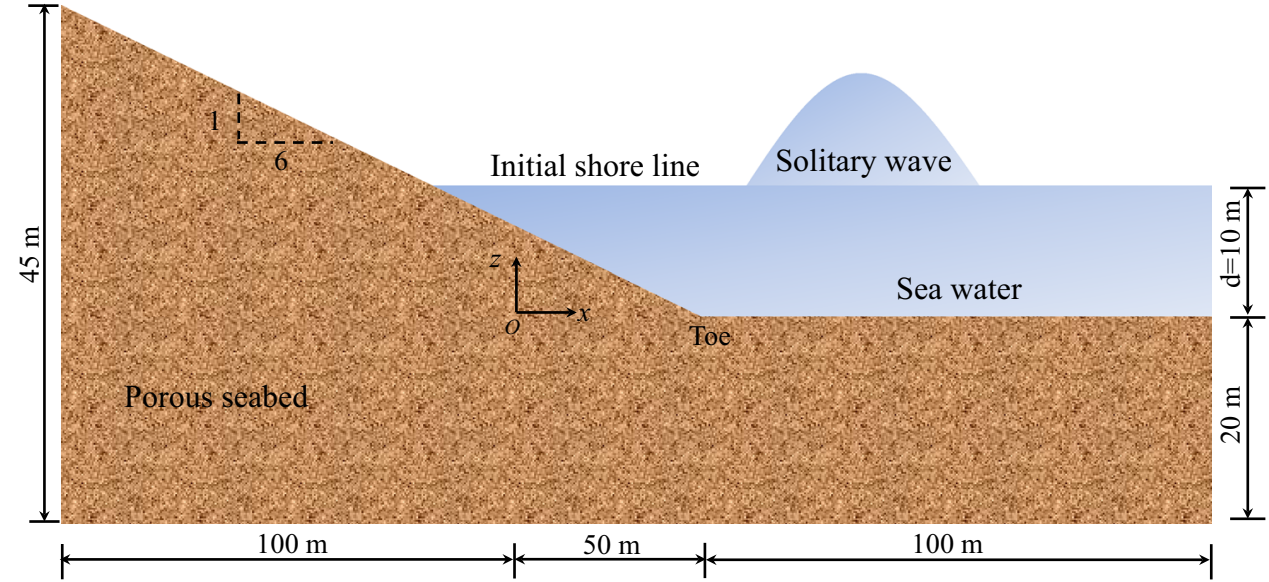

Table 1 Input data in the numerical examples

\begin{tabular}{lll}
\hline Parameter & Value & Unit \\
\hline Soil porosity $\left(n_{e}\right)$ & 0.425 & - \\
Poisson's ratio $\left(\mu_{s}\right)$ & 0.35 & - \\
Shear modulus $(G)$ & $5 \times 10^{6}$ & $\mathrm{~N} / \mathrm{m}^{2}$ \\
Soil permeability $\left(k_{s}\right)$ & $10^{-4}, 10^{-5}, 10^{-6}$ & $\mathrm{~m} / \mathrm{s}$ \\
Degree of saturation $(S)$ & 1 & - \\
Relative density $\left(D_{r}\right)$ & $0.2,0.3,0.4$ & - \\
\hline
\end{tabular}

\subsection{Wave model}

A VARANS (volume-averaged Reynolds averaged NavierStokes) solver (Lin and Liu 1999) is used to model the solitary wave run-up and drawdown, which are derived by integrating the RANS equations over the control volume. The mass and momentum conservation equations can be expressed as follows:

$$
\begin{aligned}
& \frac{\partial\left\langle\bar{u}_{f i}\right\rangle}{\partial x_{i}}=0 \\
& \frac{\partial\left\langle\bar{u}_{f i}\right\rangle}{\partial t}+\frac{\left\langle\bar{u}_{f j}\right\rangle}{n\left(1+c_{A}\right)} \frac{\partial\left\langle\bar{u}_{f i}\right\rangle}{\partial x_{j}} \\
& =\frac{1}{1+c_{A}}\left[-\frac{n}{\rho_{f}} \frac{\partial\langle\bar{p}\rangle^{f}}{\partial x_{i}}-\frac{\partial\left\langle\overline{u_{f i}^{\prime} u_{f j}^{\prime}}\right\rangle}{\partial x_{j}}+\frac{1}{\rho_{f}} \frac{\partial\left\langle\bar{\tau}_{f i j}\right\rangle}{\partial x_{j}}+n g_{i}\right] \\
& \quad-\frac{\left\langle\bar{u}_{i}\right\rangle}{1+c_{A}}\left[\frac{\alpha^{\prime}(1-n)^{2}}{n^{2} d_{50}^{2}}+\frac{\beta(1-n)}{n^{2} d_{50}} \sqrt{\left\langle\bar{u}_{f 1}\right\rangle^{2}+\left\langle\bar{u}_{f 2}\right\rangle^{2}}\right]
\end{aligned}
$$

in which $u_{f i}$ is the flow velocity, $x_{i}$ is Cartesian coordinate, $t$ is the time, $\rho_{f}$ is the density of fluid, $p$ is the pressure, $g_{i}$ is the acceleration due to gravity, $n$ and $d_{50}$ are the porosity and equivalent mean diameter of the porous material, respectively, $c_{A}$ denotes the added mass coefficient, calculated by
$c_{A}=0.34(1-n) n . \alpha$ and $\beta$ are empirical coefficients associated with the linear and nonlinear drag force, respectively, which can be determined through the fitting and regression of a wide range of experiment data, Liu et al. (1999) suggested that the $\alpha=200$ and $\beta=1.1$ for porous flow. $\tau_{f i j}$ is the viscous stress tensor of mean flow which can be defined as

$\tau_{f i j}=v_{f}\left(\frac{\partial \bar{u}_{f i}}{\partial x_{j}}+\frac{\partial \bar{u}_{f j}}{\partial x_{i}}\right)$,

where $v_{f}$ is the molecular viscosity. The over-bar represents the ensemble average in the case of waves and the prime denotes turbulent fluctuations induced by the ensemble mean. It should be noted here that since the VARANS equations (1)-(2) are also valid for steady or uncyclic unsteady flow scenarios, in this case, the over-bar denotes time averaging rather than ensemble averaging. The symbol \langle\rangle and $\left\langle{ }^{f}\right.$ stand for Darcy's volume averaging operator and the intrinsic averaging operator, respectively, and can be defined as

$\langle a\rangle=\frac{1}{\forall} \int_{\forall_{f}} a \mathrm{~d} \forall, \quad$ and $\langle a\rangle^{f}=\frac{1}{\forall^{f}} \int_{\forall_{f}} a \mathrm{~d} \forall$

in which $\forall$ is the total averaging volume, and $\forall f$ is the portion of $\forall$ that is occupied by the fluid. The relationship between the Darcy's volume averaging operator and intrinsic volume averaging is $\langle a\rangle=n\langle a\rangle^{f}$. The influence of turbulence fluctuations on the mean flow, denoted as $\left\langle u_{f i}^{\prime} u_{f j}^{\prime}\right\rangle$, is obtained by solving the volume-averaged $k-\epsilon_{f}$ equations shown as (Hsu et al. 2002):

$$
\begin{aligned}
\frac{\partial\langle k\rangle}{\partial t}+\frac{\left\langle\bar{u}_{f j}\right\rangle}{n} \frac{\partial\langle k\rangle}{\partial x_{j}}= & \frac{\partial}{\partial x_{j}}\left[\left(\frac{\left\langle v_{t}\right\rangle}{\sigma_{k}}+v\right) \frac{\partial\langle k\rangle}{\partial x_{j}}\right] \\
& -\frac{\left\langle\overline{u_{f i}^{\prime} u_{f j}^{\prime}}\right\rangle}{n} \frac{\partial\left\langle\bar{u}_{f i}\right\rangle}{\partial x_{j}}-\left\langle\epsilon_{f}\right\rangle+n \epsilon_{f \infty}
\end{aligned}
$$




$$
\begin{aligned}
\frac{\partial\left\langle\epsilon_{f}\right\rangle}{\partial t}+\frac{\left\langle\bar{u}_{f j}\right\rangle}{n} \frac{\partial \epsilon_{f}}{\partial x_{j}}= & \frac{\partial}{\partial x_{j}}\left[\left(\frac{\left\langle v_{t}\right\rangle}{\sigma_{\epsilon_{f}}}+v\right) \frac{\partial \epsilon_{f}}{\partial x_{j}}\right] \\
& \left.-C_{1 \epsilon_{f}} \frac{\left\langle\epsilon_{f}\right\rangle}{n\langle k\rangle} \overline{\left\langle u_{f i}^{\prime} u_{f j}^{\prime}\right.}\right\rangle \frac{\partial\left\langle\bar{u}_{f i}\right\rangle}{\partial x_{j}} \\
& -C_{2 \epsilon_{f}} \frac{\left\langle\epsilon_{f}\right\rangle^{2}}{\langle k\rangle}+n C_{2 \epsilon_{f}} \frac{\epsilon_{f \infty}^{2}}{k_{\infty}},
\end{aligned}
$$

where $v_{t}$ is the eddy viscosity and $v$ is the dynamic viscosity which can be expressed as $\nu_{f} / \rho_{f}$. The empirical coefficients $C_{1 \epsilon_{f}}, C_{2 \epsilon_{f}}, \sigma_{\epsilon_{f}}$ and $\sigma_{k}$ are $1.44,1.92,1.3$, and 1.0 , respectively, which are estimated from stationary flows experiment (Rodi 1993). The $\epsilon_{f \infty}, k_{\infty}$ and $v_{t}$ can be defined as

$$
\begin{aligned}
\epsilon_{f \infty} & =39.0 \frac{(1-n)^{2.5}}{n}\left(\left\langle\bar{u}_{1}\right\rangle^{2}+\left\langle\bar{u}_{2}\right\rangle^{2}\right)^{1.5} \frac{1}{d_{50}} \\
k_{\infty} & =3.7 \frac{1-n}{\sqrt{n}}\left(\left\langle\bar{u}_{1}\right\rangle^{2}+\left\langle\bar{u}_{2}\right\rangle^{2}\right) \\
\left\langle v_{t}\right\rangle & =C_{u} \frac{\langle k\rangle^{2}}{n\left\langle\epsilon_{f}\right\rangle},
\end{aligned}
$$

where $C_{u}$ is a coefficient depending on the local strain rate (Hsu et al. 2002).

The internal wave-maker method developed by Lin and Liu (1999) is used in the source region, in which a source function $S\left(x_{i}, t\right)$ is added into the mass conservation equation (1).

$\frac{\partial\left\langle u_{i}\right\rangle}{\partial x_{i}}=S\left(x_{i}, t\right)$ in $\Omega$

where $S\left(x_{i}, t\right) \neq 0$ within the source region $\Omega$. The value of $S\left(x_{i}, t\right)$ depends on wave characteristics, and its formulation for a solitary wave is given as

$S\left(x_{i}, t\right)=\frac{C H}{A} \operatorname{sech}^{2}\left[\sqrt{\frac{3 H}{4 d^{3}}}\left(x_{s}-C t\right)\right]$

in which $C$ is the wave phase velocity, $H$ is wave height, $d$ is the water depth, $A$ is the area of source region, and $x_{S}$ is used to make $s(0) \rightarrow 0$.

Regarding the mean flow field, the no-slip boundary condition is imposed on the seafloor surface $\left(u_{f i}=0\right)$. The zero-stress condition is adopted on the mean free surface $\left(\tau_{f i j}=0\right)$ while the effect of air flow is neglected. For the turbulence field, the log-law distribution of mean tangential velocity in the turbulent boundary layer is imposed in the rigid point next to seafloor. Both the turbulent kinetic energy $(k)$ and its dissipation rate $\left(\epsilon_{f}\right)$ on the free surface are implemented with zero gradient boundary conditions, (i.e. $\frac{\partial k}{\partial n}=\frac{\partial \epsilon_{f}}{\partial n}=0$, in which $n$ is the unit normal on the free surface). The damping zone located towards the seaward direction is far from the concerned region.

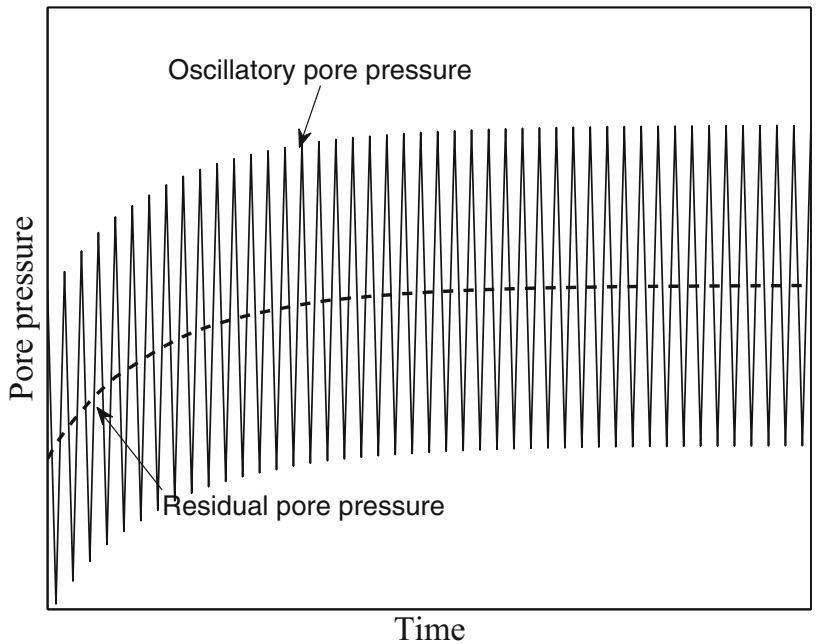

Fig. 2 Mechanisms of wave-induced pore pressures

\subsection{Seabed model}

In general, the wave-induced pore pressures within marine sediments consist of two components: oscillatory and residual mechanisms, as shown in Fig. 2, which can be expressed as

$p=\tilde{p}+\bar{p}, \quad$ where $\quad \bar{p}=\frac{1}{T} \int p d t$

where $T$ is the wave period, $p$ denotes the wave-induced dynamic pore pressures, $\tilde{p}$ represents the oscillatory component, and $\bar{p}$ represents the residual component.

\subsubsection{Oscillatory soil response}

For a two-dimensional and a hydraulically isotropic porous seabed with the permeability $k_{s}$ in all directions, Young et al. (2009) proposed that the unsaturated region of slope above the still water line had only minor influence on the pore pressure distributions on the region of interest in this study (saturated region below the subsurface water table). Therefore, it is reasonable to ideally assume a fully saturated porous sloping seabed in this study, including both regions above and below the still water level. Then, the conservation of mass leads to

$\nabla^{2} \tilde{p}-\frac{\gamma_{w} n_{s} \beta_{s}}{k_{s}} \frac{\partial \tilde{p}_{s}}{\partial t}=\frac{\gamma_{w}}{k_{s}} \frac{\partial}{\partial t}\left(\frac{\partial u_{s}}{\partial x}+\frac{\partial w_{s}}{\partial z}\right)$

in which $\tilde{p}$ is wave-induced oscillatory pore pressure, $n_{s}$ is the soil porosity, $\gamma_{w}$ is the unit weight of pore water, $k_{s}$ is the permeability of the soil, and $\beta_{s}$ is the compressibility of 
pore fluid, which is defined by

$\beta_{s}=\frac{1}{K_{w}}+\frac{1-S}{P_{w 0}}$,

where $K_{w}$ is the true modulus of elasticity of water (taken as $\left.2 \times 10^{9} \mathrm{~N} / \mathrm{m}^{2}\right), P_{w o}$ is the absolute water pressure, and $S$ is the degree of saturation. For a fully saturated seabed, $\beta_{s}=1 / K_{w}$

Neglecting the inertia terms, the governing equations for the force equilibrium in the soil can be written as

$$
\begin{array}{r}
\frac{\partial \sigma_{x}^{\prime}}{\partial x}+\frac{\partial \tau_{x z}}{\partial z}=\frac{\partial \tilde{p}}{\partial x} \\
\frac{\partial \tau_{x z}}{\partial x}+\frac{\partial \sigma_{z}^{\prime}}{\partial z}+\rho g=\frac{\partial \tilde{p}}{\partial z}
\end{array}
$$

where $\sigma_{x}^{\prime}$ and $\sigma_{z}^{\prime}$ are effective normal stresses in the $x$ - and $z$-directions, respectively, and $\tau_{x z}$ is the shear stress, $\rho=$ $\rho_{f} n_{s}+\rho_{s}\left(1-n_{s}\right)$ is the average density of porous seabed, $\rho_{f}$ is fluid density, $\rho_{s}$ is solid density, and $g$ is the gravitational acceleration.

Based on Hooke's law, the relationship between the elastic incremental effective stresses and displacements are given by

$$
\begin{aligned}
& \sigma_{x}^{\prime}=2 G\left[\frac{\partial u_{s}}{\partial x}+\frac{\mu_{s} \varepsilon_{s}}{1-2 \mu_{s}}\right] \\
& \sigma_{z}^{\prime}=2 G\left[\frac{\partial w_{s}}{\partial x}+\frac{\mu_{s} \varepsilon_{s}}{1-2 \mu_{s}}\right] \\
& \tau_{x z}=G\left[\frac{\partial u_{s}}{\partial z}+\frac{\partial w_{s}}{\partial x}\right],
\end{aligned}
$$

where $G$ is shear modulus of soil, which is related to Young's modulus $(E)$ and Poisson's ratio $\left(\mu_{s}\right)$ as $E / 2\left(1+\mu_{s}\right), u_{s}$ and $w_{s}$ are the soil displacements in the $x$-and $z$-directions, respectively. Substituting (17)-(19) into (15)-(16), the equations of force balance can be rewritten as

$$
\begin{aligned}
G \nabla^{2} u_{s}+\frac{G}{1-2 \mu_{s}} \frac{\partial \varepsilon_{s}}{\partial x} & =\frac{\partial \tilde{p}}{\partial x} \\
G \nabla^{2} w_{s}+\frac{G}{1-2 \mu_{s}} \frac{\partial \varepsilon_{s}}{\partial z}+\rho g & =\frac{\partial \tilde{p}}{\partial z}
\end{aligned}
$$

in which $\nabla^{2}$ is the Laplace operator and $\varepsilon_{S}$ is the volumetric strain which can be defined as

$\varepsilon_{s}=\frac{\partial u_{s}}{\partial x}+\frac{\partial w_{s}}{\partial z}$

\subsubsection{Residual soil response}

The residual pore pressure in a homogeneous, isotropic soil can be derived from 1-D Biot's consolidation equation (Sumer and Fredsøe 2002; Jeng 2013), which can be further extended to 2D case (Jeng and Zhao 2014) with the following governing equation:

$$
\frac{\partial \bar{p}}{\partial t}=c_{v}\left(\frac{\partial^{2} \bar{p}}{\partial x^{2}}+\frac{\partial^{2} \bar{p}}{\partial z^{2}}\right)+f(x, z, t),
$$

where $\bar{p}_{S}$ denote the wave-induced residual pore pressure, and $c_{v}$ is coefficient of consolidation based on plain strain which can be defined as

$$
c_{v}=\frac{G k_{s}}{\gamma_{w}\left(1-2 \mu_{s}\right)}
$$

The source term for pore pressure accumulation in (23) is re-defined as a $2 \mathrm{D}$ time-dependent function in which the phase-resolved absolute shear stress is considered (Jeng and Zhao 2014),

$f(t)=\frac{\sigma_{0}^{\prime}}{T}\left[\frac{\left|\tilde{\tau}_{i n s}(x, z, t)\right|}{\alpha_{r} \sigma_{0}^{\prime}}\right]^{-\frac{1}{\beta_{r}}}$

in which $\left|\tilde{\tau}_{\text {ins }}(x, z, t)\right|$ is the absolute value of phase-resolved oscillatory shear stress, and $\alpha_{r}$ and $\beta_{r}$ are two empirical coefficients which can be estimated by the empirical expressions (Sumer et al. 2012)

$\alpha_{r}=0.34 D_{r}+0.084$, and $\beta_{r}=0.37 D_{r}-0.46$,

where $D_{r}$ is the relative density of the soil.

Regarding the phase-resolved shear stress, some comments must be addressed to avoid misleading the readers. The phase-resolved shear stress is not the constant shear stress amplitude (McDougal et al. 1989; Sumer and Fredsøe 2002; Jeng 2013), but the instant shear stress which is related to the incidence of wave phases. This new definition can provide a more appropriate estimation for the time variation of shear stress with respect to the complicated interaction between solitary wave and sloping seabed. However, this model is not able to achieve the continuous changes in the direction of shear stress that normally take place during the run-up and drawdown phases of a solitary wave. This brought remarkable contrasts in the residual responses, as pointed out by Sassa and Sekiguchi (2001). Therefore, this paper can only provide the first-hand approximation for the accumulation of residual pore pressure with respect to the solitary wave and sloping seabed interaction.

In addition to the new 2D definition of source term, we consider the effects of configuration of sloping seabed on the initial consolidation status. Then the effective normal stresses $\left(\sigma_{0}^{\prime}\right)$ can be expressed as

$\sigma_{0}^{\prime}=\frac{1+\mu_{s}}{3}\left(\sigma_{z 0}^{\prime}+\sigma_{x 0}^{\prime}\right)$ 
where $\sigma_{x 0}^{\prime}$ and $\sigma_{z 0}^{\prime}$ are the initial effective stress under static water pressures in the $x$ - and $z$-directions, respectively.

\subsubsection{Boundary conditions}

Appropriate boundary conditions are required for the evaluation of the wave-induced soil response. Firstly, the vertical effective normal stress vanishes and the pore pressure is equal to the wave pressure obtained from the wave model at the surface of the porous sloping seabed, while the residual pore pressure are assumed as zero at the surface of the seabed,

$\tilde{p}=P_{b}, \quad \sigma_{z}^{\prime}=\tau_{x z}=0, \quad \bar{p}=0$,

Second, zero displacements and no vertical flow occur at the bottom of the seabed $(z=-h)$; then we have

$\frac{\partial \tilde{p}}{\partial z}=0, \quad \frac{\partial \bar{p}}{\partial z}=0, \quad u_{s}=w_{s}=0$

Third, both lateral boundaries of seabed are assumed as zero-flux, zero horizontal displacement boundaries. The left and right boundaries are purposely placed far enough away such that the effect of the lateral boundary conditions can be ignored in the region of interest (Ye and Jeng 2012).

\subsection{Integration of wave and seabed models}

In the computation, the wave model is responsible for the simulation of the solitary wave run-up and drawdown over sloping seabed as well as the pressure acting on the seabed. Due to the fact that the poro-elastic deformations of seabed are small and there is no feedback loop in the proposed integrating process, it is a semi-coupling process. Since fluid velocity and flux have little effect on the dynamic response of seabed foundation (Bierawski and Maeno 2004), we only consider the continuity of pressure at the interface between the fluid domain and the porous medium in the whole semi-coupling process. After that, the seabed model is solved to obtain oscillatory seabed response, including pore water pressure, soil displacement, and effective shear stress. Then, the oscillatory shear stresses will be included in the source term and the residual soil response will be determined through Eq. (23). It should be noted here that liquefaction due to the build-up of residual pore pressure takes place in complete concert with substantial amplification of oscillatory pore pressure due to the volumetric contraction of the soil under cyclic loadings. Basically, the present model is based on poro-elastic model where the oscillatory and residual pore pressure cannot be simultaneously investigated. In order to consistently predict such coupling physics and processes of the liquefaction, a more sophisticated elasto-plastic consti- tutive model such as Sassa and Sekiguchi (2001)'s model is required in the future.

\section{Validation of the present model}

The validations of the proposed model consists of three cases. (a) The wave model is verified through comparison with surface profiles from solitary wave run-up experiments on sloping beach (Synolakis 1987). (b) We compare our model with the laboratory experiments for the wave-induced oscillatory pore pressure in a porous sloping seabed (Sumer et al. 2011). (c) The integrated model is verified with the laboratory experiments and analytical solutions for the residual pore pressure in a porous flat seabed (Sumer et al. 2012).

There are numerous experimental studies for the tsunami effects on coastal regions since 1950s. One of the examples for the solitary wave run-up is given by Synolakis (1987), in which a series of laboratory experiments were presented in a 40-m wave-tank facility. The solitary wave with a relative wave height up to $H / d=0.3$ propagates over a rigid, impermeable slope with a nominal $1: 19.85$ slope. The toe was located at $x / d=19.85$ and the initial solitary wave at $x / d=24.42$. The initial water depth $d=1 \mathrm{~m}$, which varies from 0.21 to $0.29 \mathrm{~m}$. Figure 3 , illustrates the comparison between the measured surface profiles with the current numerical results for $H / d=0.3$. As shown in the figure, the time of breaking predicted by the present model occurs at $t \sqrt{g / d} \approx 20$, which is consistent with the experimental results reported in Synolakis (1987). A good agreement during the whole processes including wave shoaling, breaking, run-up, drawdown, and hydraulic jump demonstrates that the wave model is reliable.

Recently, Sumer et al. (2011) conducted wave flume tests to analyze the variation of pore water pressure within a sloping seabed under breaking solitary waves. The experiments were conducted on a sloping foundation with 1:14 slope in a wave flume, $28 \mathrm{~m}$ in length, $0.8 \mathrm{~m}$ in depth, and $0.6 \mathrm{~m}$ in width. The incoming solitary waves were generated by a piston-type wave generator, and the initial wave height ratio to the still water level was 0.1775 . Detailed measurements were conducted at 8 sections. The input seabed parameters in the validation are given here: soil permeability $\left(k_{S}\right)=3.5 \times 10^{-6} \mathrm{~m} / \mathrm{s}$; soil porosity $\left(n_{s}\right)=0.45$; shear modulus $(G)=5 \times 10^{6} \mathrm{~N} / \mathrm{m}^{2}$; the degree of saturation $(S)=0.99$; Poisson's ratio $\left(\mu_{s}\right)=0.35$. The comparison between the present numerical results and experimental data (Sumer et al. 2011) for the time variations and depth variations of pore pressure are shown in Fig. 4a, b, respectively. As shown in the figure, there exists a phase lag in the time variation of pore pressure during the hydraulic jump phase between the numerical solutions and experimental data. This may be attributed to the difficulty in simulating the wave- 

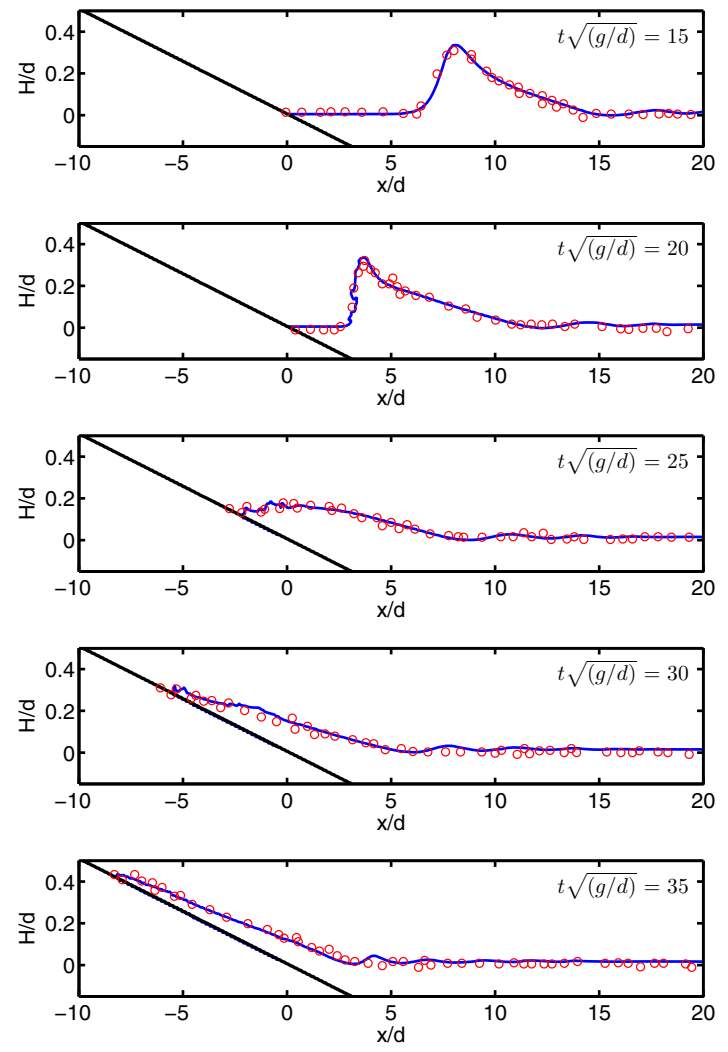
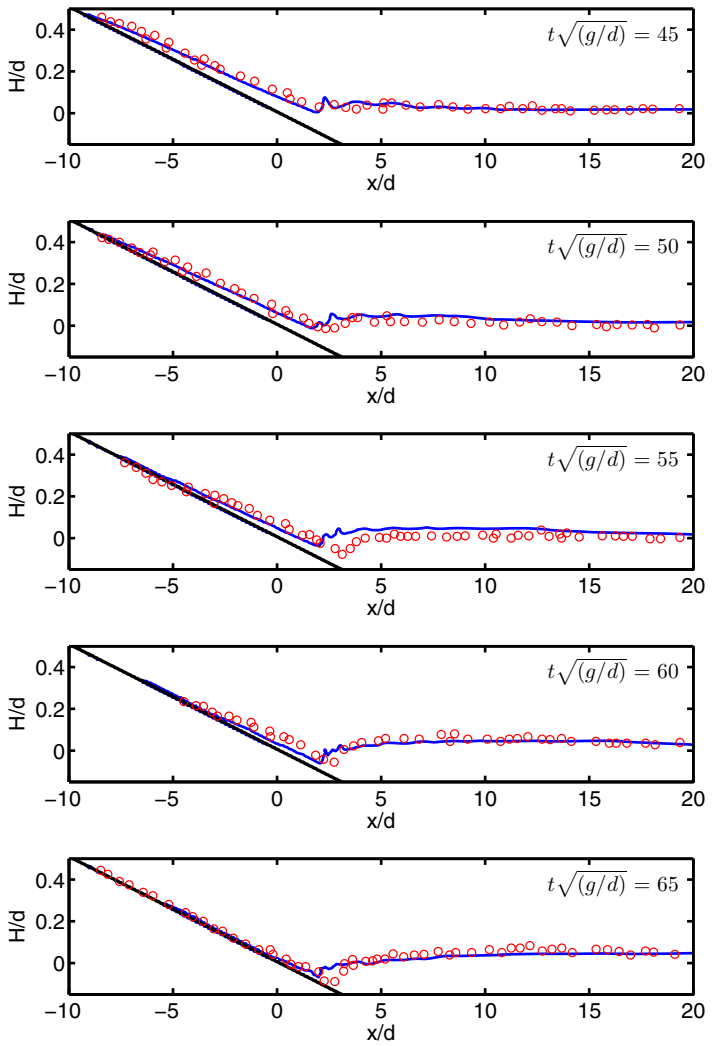

Fig. 3 Surface profiles of a solitary wave on a 1:19.85 plane beach for $H / d=0.3$. Notation: lines numerical results, and opencircles experimental data (Synolakis 1987)

seabed interaction through numerical modeling during the hydraulic jump phase, where very complicated oscillations are formed due to the hydraulic jump following the drawdown phase. However, the overall trends including the peak positive and peak negative value are satisfactory.

Since there is not enough quantitative laboratory or field data to examine wave-induced residual mechanisms in a slope subject to solitary wave run-up and drawdown, a possible verification of the present model for the residual pore pressure is through the reduction of this model to the flat seabed foundation subject to progressive wave loading. In this study, the wave-induced residual pore pressure in a porous flat seabed is compared with experimental data conducted by Sumer et al. (2012). The input data are given here: wave period $(T)=1.6 \mathrm{~s}$; wave height $(H)=0.18 \mathrm{~m}$; water depth $(d)=0.55 \mathrm{~m}$; soil permeability $\left(k_{s}\right)=1.5 \times 10^{-5} \mathrm{~m} / \mathrm{s}$; soil porosity $\left(n_{s}\right)=0.51$; shear modulus $(G)=1.92 \times$ $10^{6} \mathrm{~N} / \mathrm{m}^{2}$; seabed thickness $(h)=0.4 \mathrm{~m}$; Poisson's ratio $\left(\mu_{s}\right)=0.29 ;$ Consolidation coefficient $\left(c_{v}\right)=0.0127 \mathrm{~m}^{2} / \mathrm{s}$; Relative density of soil $\left(D_{r}\right)=0.28$; coefficient of lateral earth pressure $\left(K_{0}\right)=0.42$; degree of saturation $S=1.0$; and submerged specific weight of soil $\left(\gamma^{\prime}\right)=8.14 \mathrm{KN} / \mathrm{m}^{3}$. As shown in Fig. 5, the present model provides a reasonable good prediction of the wave-induced residual pore pressure, compared with the experimental data.

\section{Results and discussions}

\subsection{Consolidation of sloping seabed}

In real ocean environments, seabed generally has experienced the consolidation process under the self-gravity and seawater loading in the geological history. The liquefied state of a seabed is commonly determined by $\bar{p}=\sigma_{0}^{\prime}$ (Sumer and Fredsøe 2002; Jeng 2013). Therefore, the initial effective stress $\sigma_{0}^{\prime}$ is a key factor in the analysis of the wave-induced residual liquefaction. The mean initial effective stress $\sigma_{0}^{\prime}$ is normally defined as $\sigma_{0}^{\prime}=\left(1+2 K_{0}\right) \gamma^{\prime} z / 3$. For a flat seabed foundation, $\gamma^{\prime}$ is the submerged specific weight of the soil. However, for a sloping seabed with complicated configuration, this definition for the prediction of the initial effective stress may be inappropriate. Therefore, it is necessary to determine the initial consolidation state for a sloping seabed before wave loading being applied to the numerical model. In this study, the initial consolidation state of the seabed is calculated using the present model under static loads including the static water pressure and self-gravity; then this consolidation status is taken as the initial condition for the wave-sloping seabed interaction problem.

Figure 6 illustrates the distribution of the effective stress and displacements in the porous sloping seabed under 


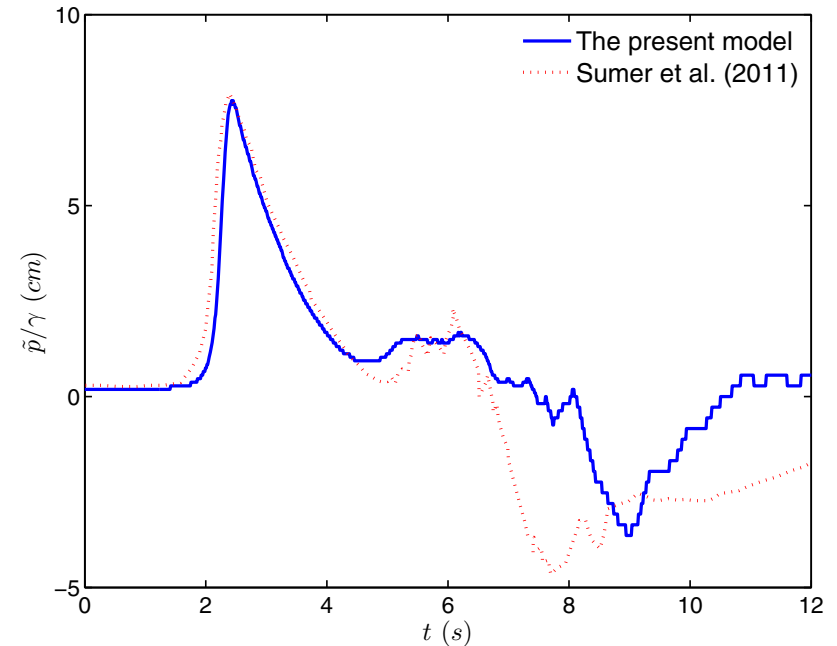

(a) $(x, z)=(-463,0) \mathrm{cm}$

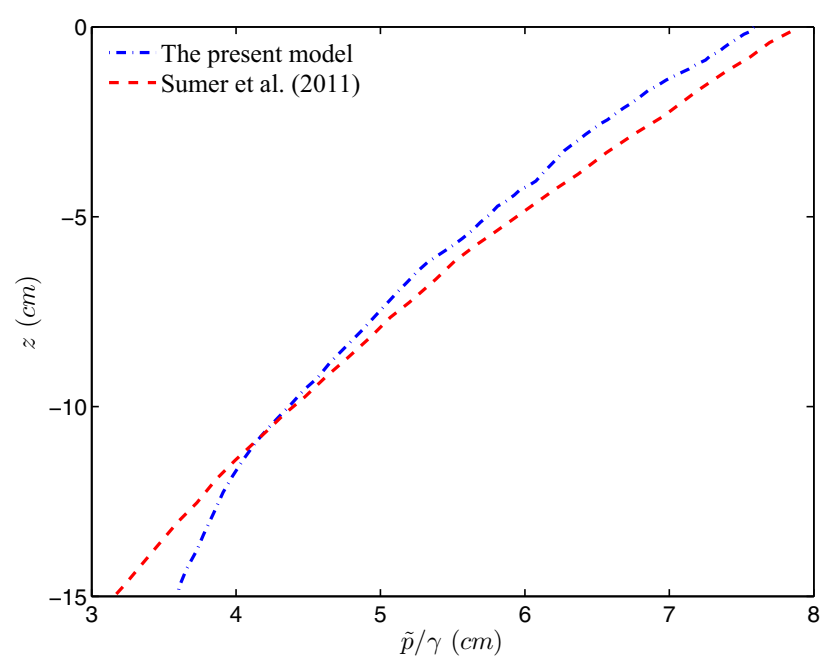

(b) $x=-463 \mathrm{~cm}$

Fig. 4 a Time history of the pore pressure variation at $(x, z)=$ $(-463,0) \mathrm{cm}$. b Distribution of pore water pressure across the bed soil depth at $t=2.4 \mathrm{~s}, x=-463 \mathrm{~cm}$

hydrostatic loading after the seabed foundations consolidate adequately (It should be emphasize that only the results in the range $x=-100$ to $150 \mathrm{~m}$ are shown). It is found that the distribution of the effective stress as well as the horizontal and vertical displacements is related to the gradient of the slope. The minimum effective stress occurs in the region along the seabed surface. In this region, the excess pore pressure can easily exceed the reduced effective overburden pressure, which will cause the sand to liquefy. The effects of slope configuration on the stress field basically disappear in the flat region of seabed, with a layered distribution of the initial effective stress, which comes from the self-gravity of seabed soil and static water pressures. The magnitude of horizontal and vertical displacement is approximately 150 and $800 \mathrm{~mm}$, respectively.

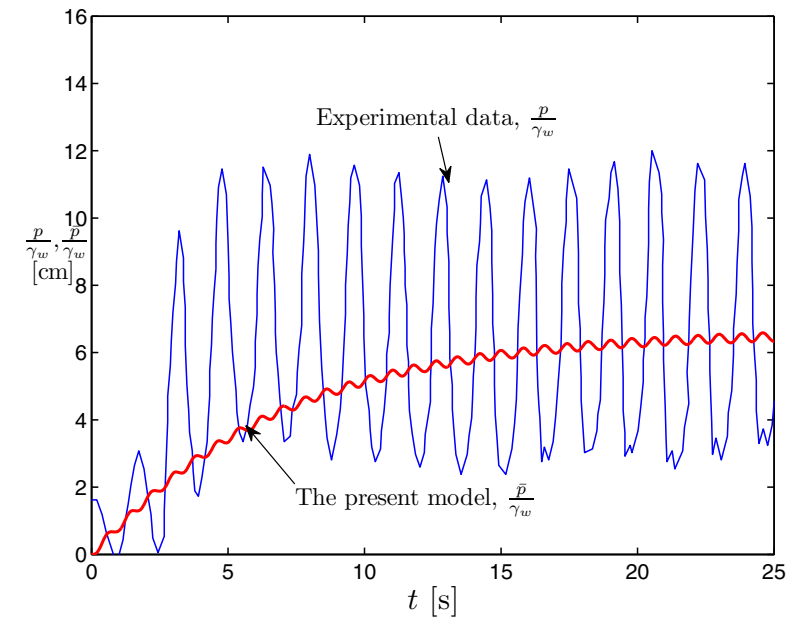

(a) $(\boldsymbol{x}, \boldsymbol{z})=(0,-0.085) \mathrm{m}$

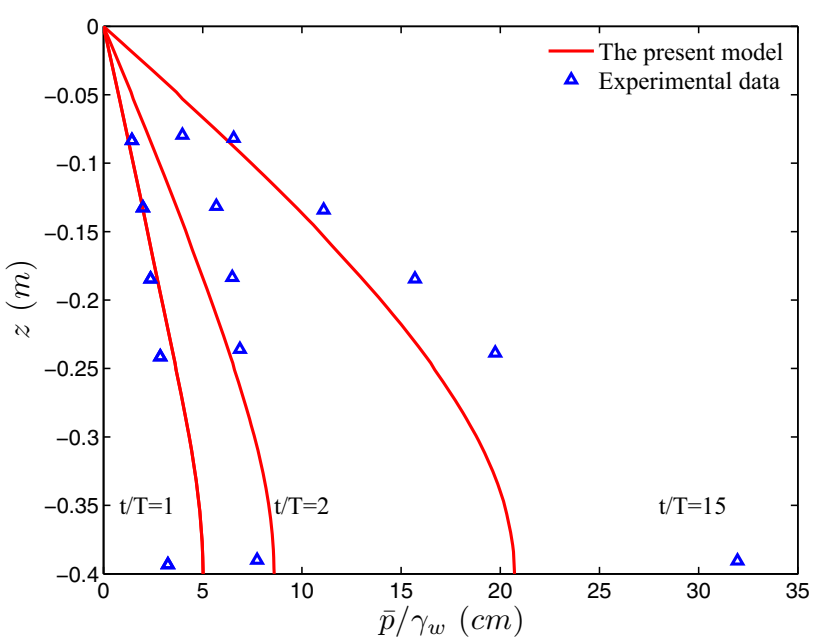

(b) $\boldsymbol{x}=0 \mathrm{~m}$

Fig. 5 Comparison of model results and experimental data. Notation: symbols experimental data (Sumer et al. 2012), solid lines the present 2-D model

\subsection{Wave profiles}

A solitary wave with the amplitude of $4.5 \mathrm{~m}$ in the seawater over the initial water depth of $10 \mathrm{~m}$ propagation over a 1:6 slope is illustrated in Fig. 7a. The wave maker is located at $400 \mathrm{~m}$, which is $350 \mathrm{~m}$ far away from the toe of the beach. This long distance could make the wave become more mature before arriving at the sloping seabed. It takes approximately $38.5 \mathrm{~s}$ for the wave reaching the shoreline, during which no obvious shoaling and wave-breaking processes are observed. The solitary wave arrives at and begins running up over the slope at $t \approx 38.5 \mathrm{~s}$, after which the run-up begins. The maximum run-up occurs at $t \approx 48.5 \mathrm{~s}$ with the maximum horizontal excursion at $x \approx 80 \mathrm{~m}$. Then the wave starts to retreat under gravity, this drawdown flow is strong enough to move the shoreline in a seaward direction, resulting in an area 
Fig. 6 The distribution of the initial mean effective stress and displacements after consolidation in sloping seabed
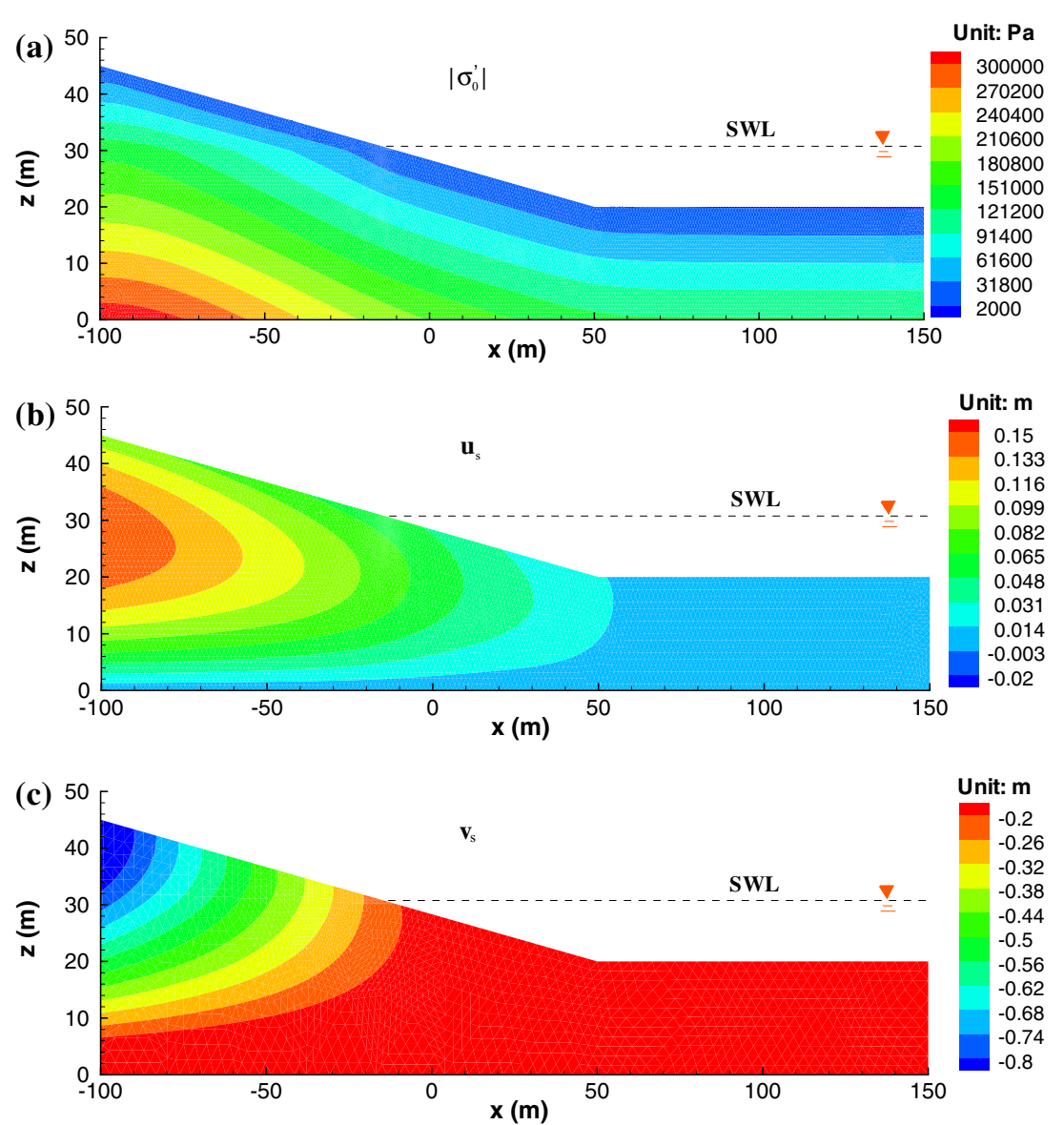

along the bed surface below the initial shoreline, where an upward seepage force which is associated with the phase lag and amplitude decay in the oscillatory pore pressures can be observed. Regarding the seepage flow, it is well recognized that the direction of the seepage force is directly related to the wave phases (Jeng 2013). The upward seepage force leading to the decompression of the soil normally occurs during the passage of wave troughs, while, on the other hand, the downward seepage force leading to the compression of the soil normally occurs during the passage of wave crests. A hydraulic jump is formed at $x \approx 0$ m during the wave drawdown, and the maximum drawdown depth is approximately $2 \mathrm{~m}$. The turbulence model, volume-averaged $k-\epsilon$ model, would become especially important when considering the complicated interaction processes between the solitary wave and sloping seabed. The wave generated by the hydraulic jump travels offshore and gradually returns to its static status, which lasted for approximately $15 \mathrm{~s}$.

The whole processes including shoaling, wave breaking, run-up, drawdown and trailing wave in the case of a 1:15 slope are plotted in Fig. 7b. The wave shoaling can be observed at $t=41.5 \mathrm{~s}$ after wave arriving at the toe of the slope and before wave-breaking, during which the water depth over the sloping seabed gradually decreases. The decrease in water depth $(d)$ results in the decrease in the wave length $(L)$ with a fixed wave period. When the wave height $(H)$ is the same, decrease of the wave length will lead to large wave steepness $(H / L)$ resulting in the wave breaking which occurs before the wave arriving at the slope at $t=47.5 \mathrm{~s}$, after which this breaking wave starts to run-up. The maximum run-up for the $1: 15$ slope occurs at $t \approx 67.5 \mathrm{~s}$, with the maximum horizontal excursion at $x \approx-205 \mathrm{~m}$. Approximately $8 \mathrm{~s}$ later, the wave drops down to its lowest point which is about $1 \mathrm{~m}$ below the still water level, while the width of the area where the seepage force is upward reaches up to approximately $50 \mathrm{~m}$, which is much wider than the 1:6 slope. These results coincide well with previous numerical results presented by Young et al. (2009). A trailing wave occurs during the hydraulic jump process; this vibration propagates to the coastal line progressively. The duration of the solitary wave run-up and drawdown processes over 1:15 slope is about $55 \mathrm{~s}$, which is much longer than that over 1:6 slope.

\subsection{Wave-induced oscillatory mechanisms}

As introduced previously, the solid-pore fluid interactions in this study are determined from Biot's consolidation equations. That is, the phase-resolved shear stress included in the source term for determining the residual soil response based on Eq. (23) is obtained from the wave-induced oscillatory 

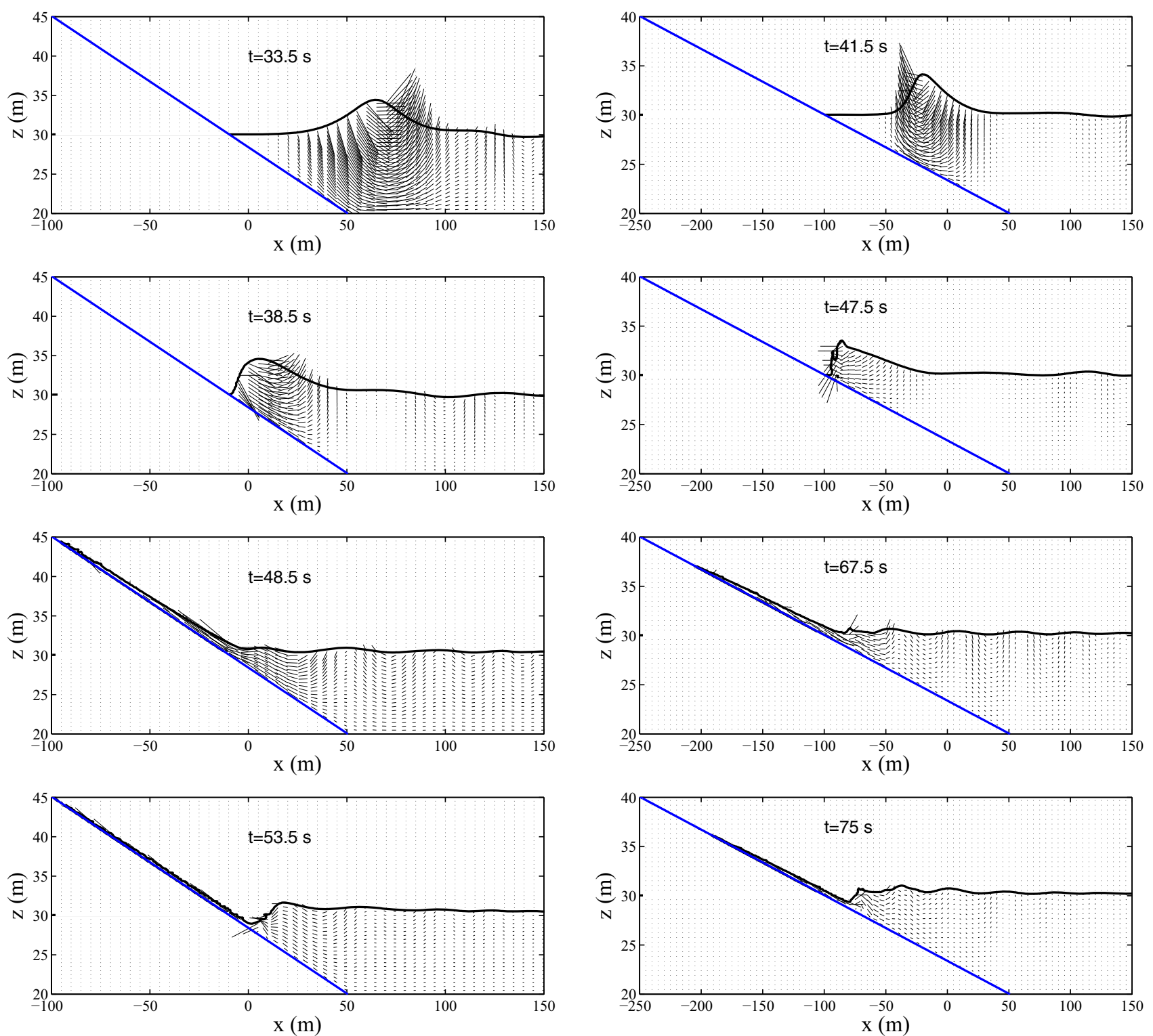

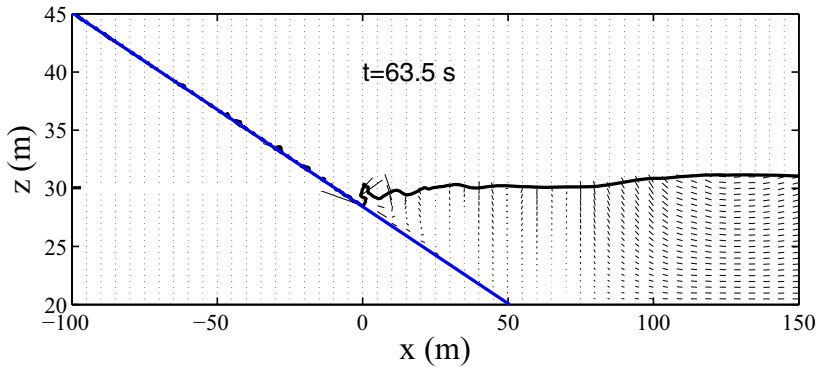

(a) 1:6 slope

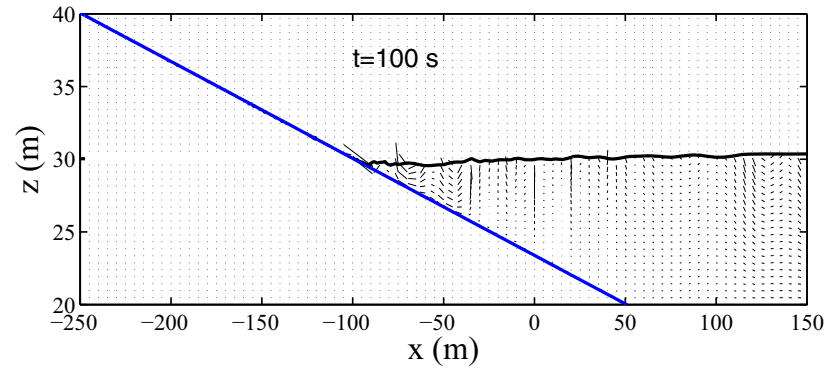

(b) 1:15 slope

Fig. 7 Surface profiles of a solitary wave on a 1:6 and 1:15 plane beach for $H / d=0.45$

soil response. Consequently, it is necessary to examine the variation of oscillatory mechanisms including the oscillatory pore pressure and shear stress during the whole interaction processes between the solitary waves and sloping seabed foundation.
The contours of the wave-induced oscillatory pore pressure in the 1:6 and 1:15 slope seabed at different time are illustrated in Fig. 8. As shown in the figure, the distribution of the wave-induced oscillatory pore pressure is highly related to the surface elevation of the solitary wave. An 

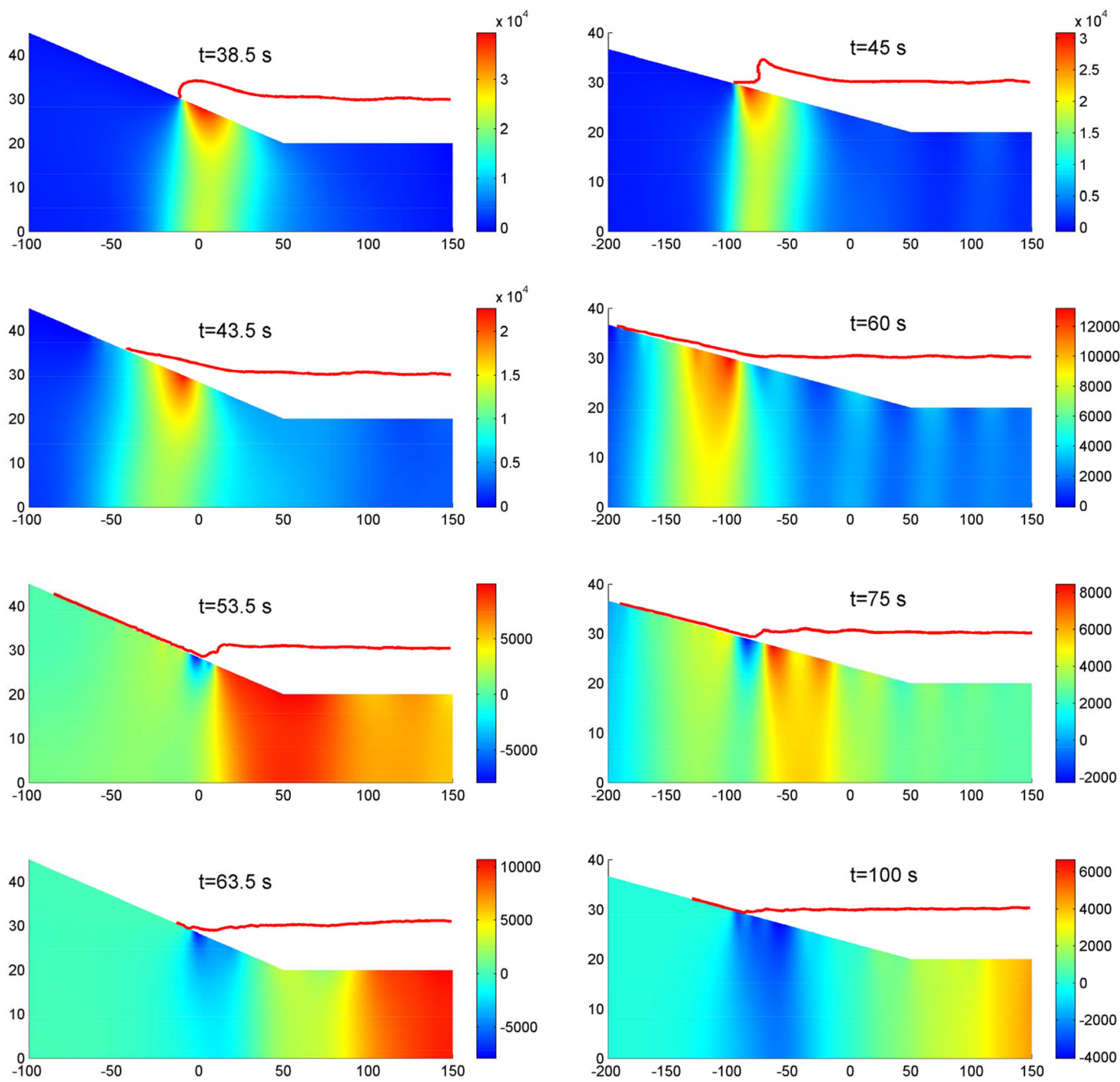

(a) 1:6 slope

(b) 1:15 slope

Fig. 8 The distributions of wave-induced oscillatory pore pressure $(\tilde{p})$ at different times for a 1:6 slope and $\mathbf{b} 1: 15$ slope

increase of pore pressure is observed in the region between the initial shoreline and downward seabed surface, when the solitary wave arrives at the sloping seabed. Due to the fact that the wave breaks prior to reaching the seabed for a $1: 15$ slope, the magnitude of the wave-induced pore pressure is smaller than that in a 1:6 slope. The pore pressures are kept decreasing as the wave propagates onshore due to energy dissipation induced by the wave-seabed interaction. Meanwhile, the area over the still water level is full of sea water when the wave run-up occurs. The pore pres- sure within the soil close to the hydraulic jump will increase again induced by the drawdown wave. It is interesting to observe that the peak negative value of the pore pressure in a 1:6 slope is greater than that in a 1:15 slope during the hydraulic jump phase. This phenomenon can be attributed to the high rate of bed surface loading and unloading induced by a steep 1:6 slope, after which the pore pressure continues to decrease until the shoreline moves back to its original position. The phenomenon of dynamic shear stress within slope seabed subject to solitary run-up and drawdown is 

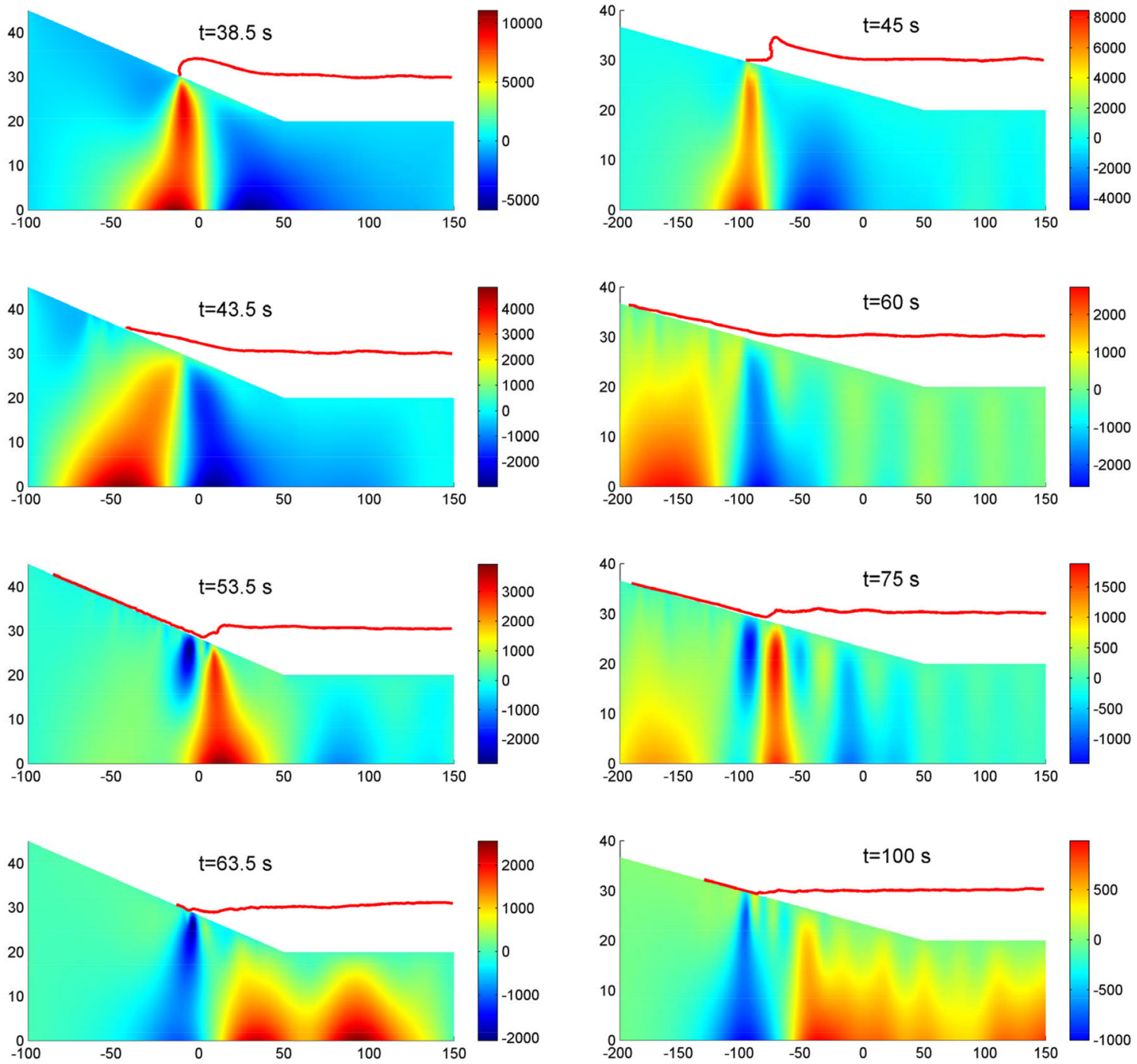

(a) 1:6 slope

(b) 1:15 slope

Fig. 9 The distributions of wave-induced dynamic shear stresses $\left(\tau_{x z}\right)$ at different times for a 1:6 slope and $\mathbf{b}$ 1:15 slope

similar to that of wave-induced pore pressure, as shown in Fig. 9.

\subsection{Distribution of wave-induced pore pressure along the $x$-direction}

Two typical sections are selected for the analysis in this study. One is located at the intersection between the initial shore line and the seabed surface $(x=-10 \mathrm{~m}$ for 1:6 slope; and $x=-100 \mathrm{~m}$ for $1: 15$ slope) where the peak positive value in pore pressure may be observed induced by great wave energy due to gradual decrease in water depth. The other is located in the hydraulic jump location ( $x=0 \mathrm{~m}$ for 1:6 slope; and $x=-85 \mathrm{~m}$ for 1:15 slope), where the maximum drop in water level is observed with accompanying peak negative value in pore pressure. Three representative points located at $0.3 \mathrm{~m}$ below the seabed surface are selected to examine the variation of wave-induced pore pressure between these two sampled sections. It can be observed from Fig. 10 that, for a 1:6 slope, as the $H / d$ increases at the coordinate which is close to the slope and far away from the hydraulic jump, an increase in the peak positive value of the pore pressure is observed. For the 1:15 slope, the variations are contrary to previous case. The peak positive value of pore pressure decreases as the coordinate close to the slope, because that the water depth $(d)$ could not decrease as fast as the wave height $(H)$ goes due to wave breaking. This is also the reason why the peak value of pore pressure for a 1:15 slope is smaller than that for a 1:6 slope. In general, the maximum drawdown depth occurs at the hydraulic jump location, where the magnitude of the upward seepage force is most significant. The peak negative value of pore pressure decreases as 


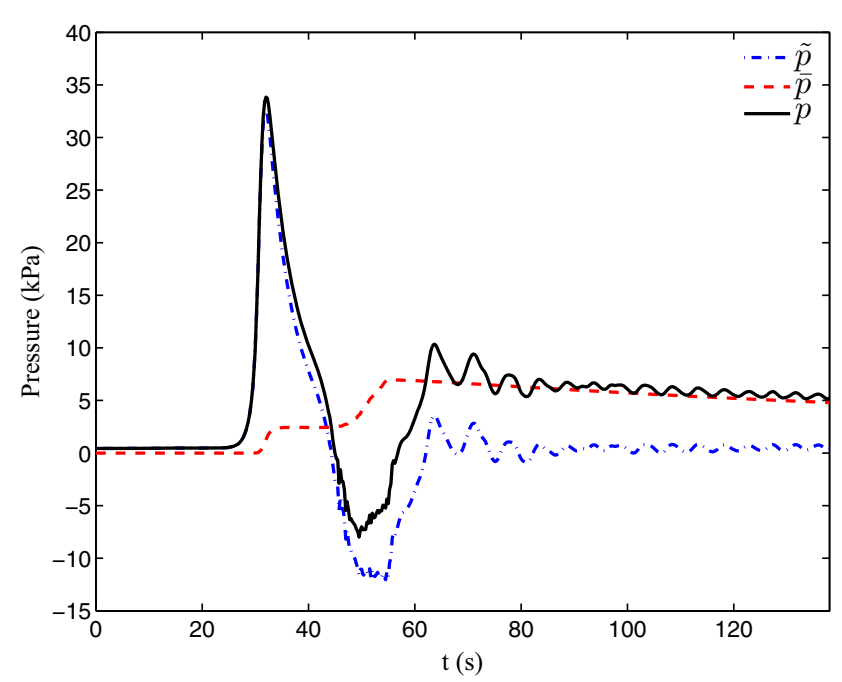

(a1) $\mathrm{x}=0 \mathrm{~m}$

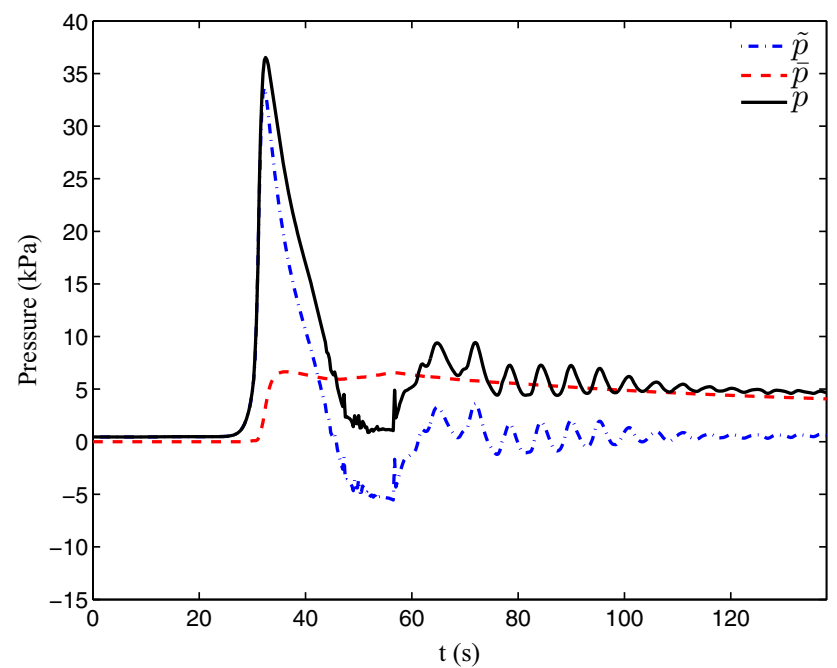

(a2) $\mathrm{x}=-5 \mathrm{~m}$

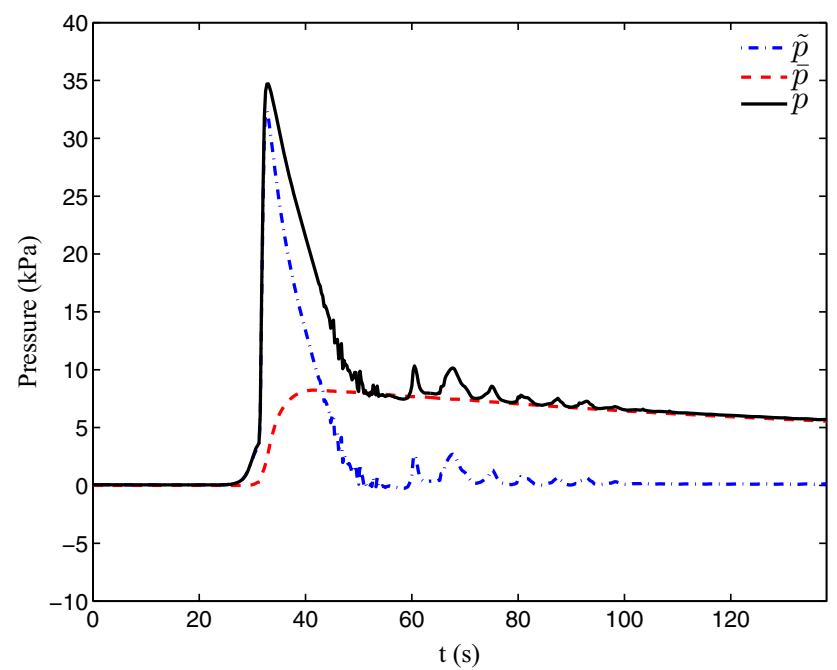

(a3) $\mathrm{x}=-10 \mathrm{~m}$

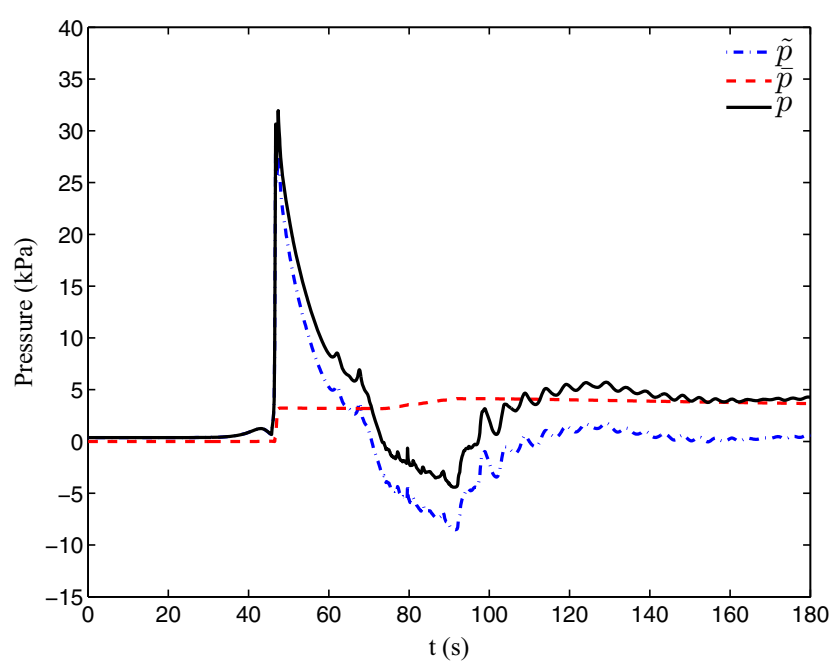

(b1) $x=-85 \mathrm{~m}$

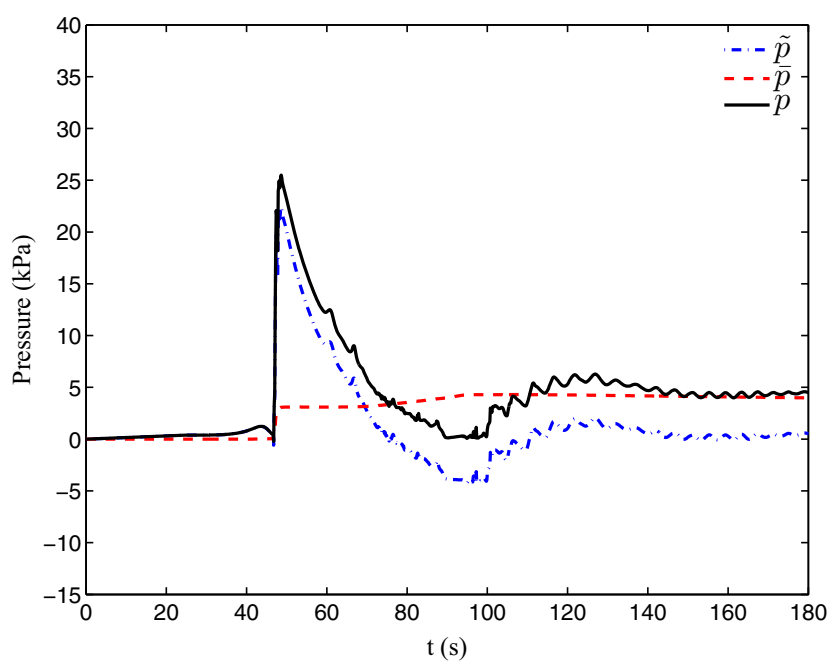

(b2) $\mathrm{x}=-92.5 \mathrm{~m}$

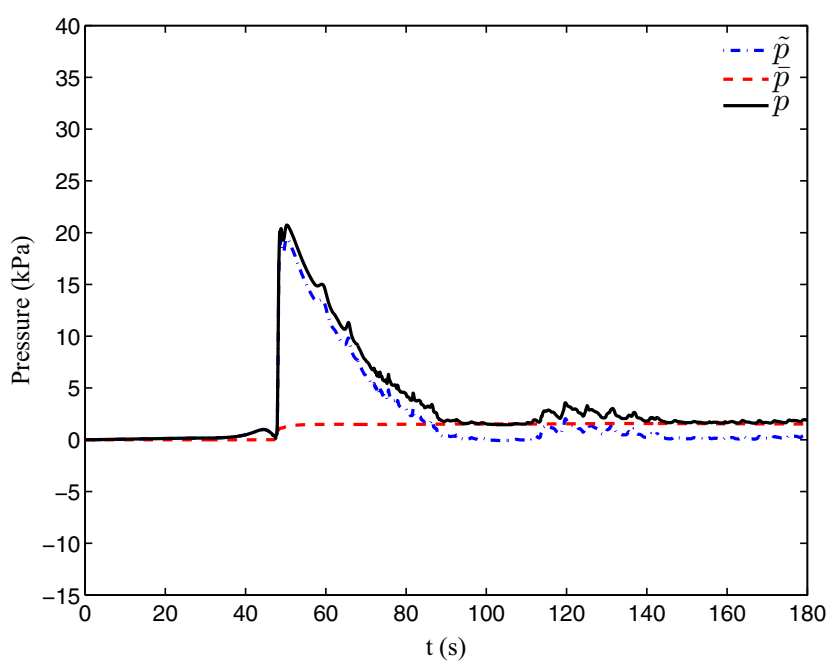

(b3) $\mathrm{x}=-100 \mathrm{~m}$

Fig. 10 Time variation of wave-induced pore pressure at three representative locations for a 1:6 slope and b 1:15 slope 

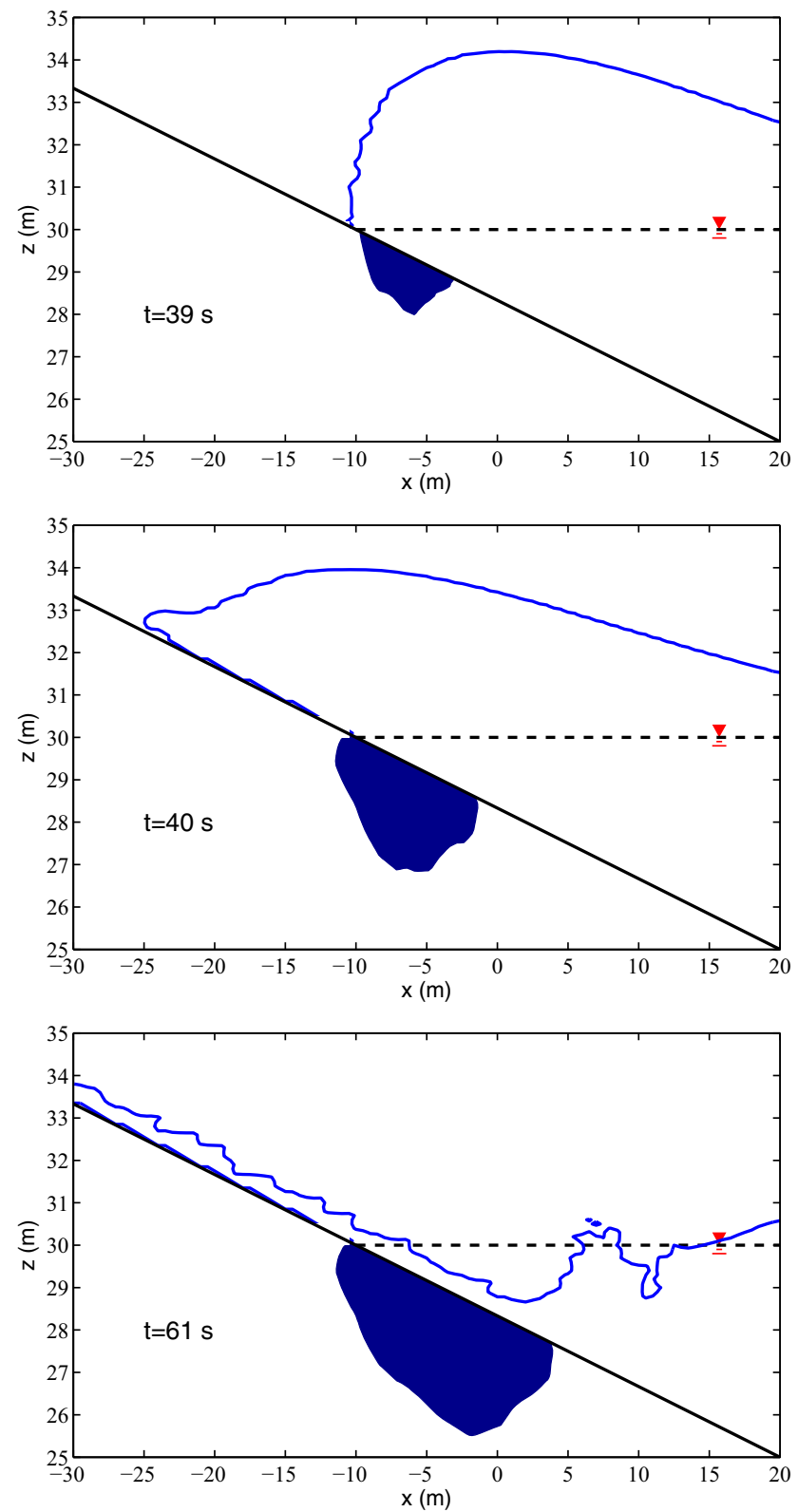

(a) 1:6 slope
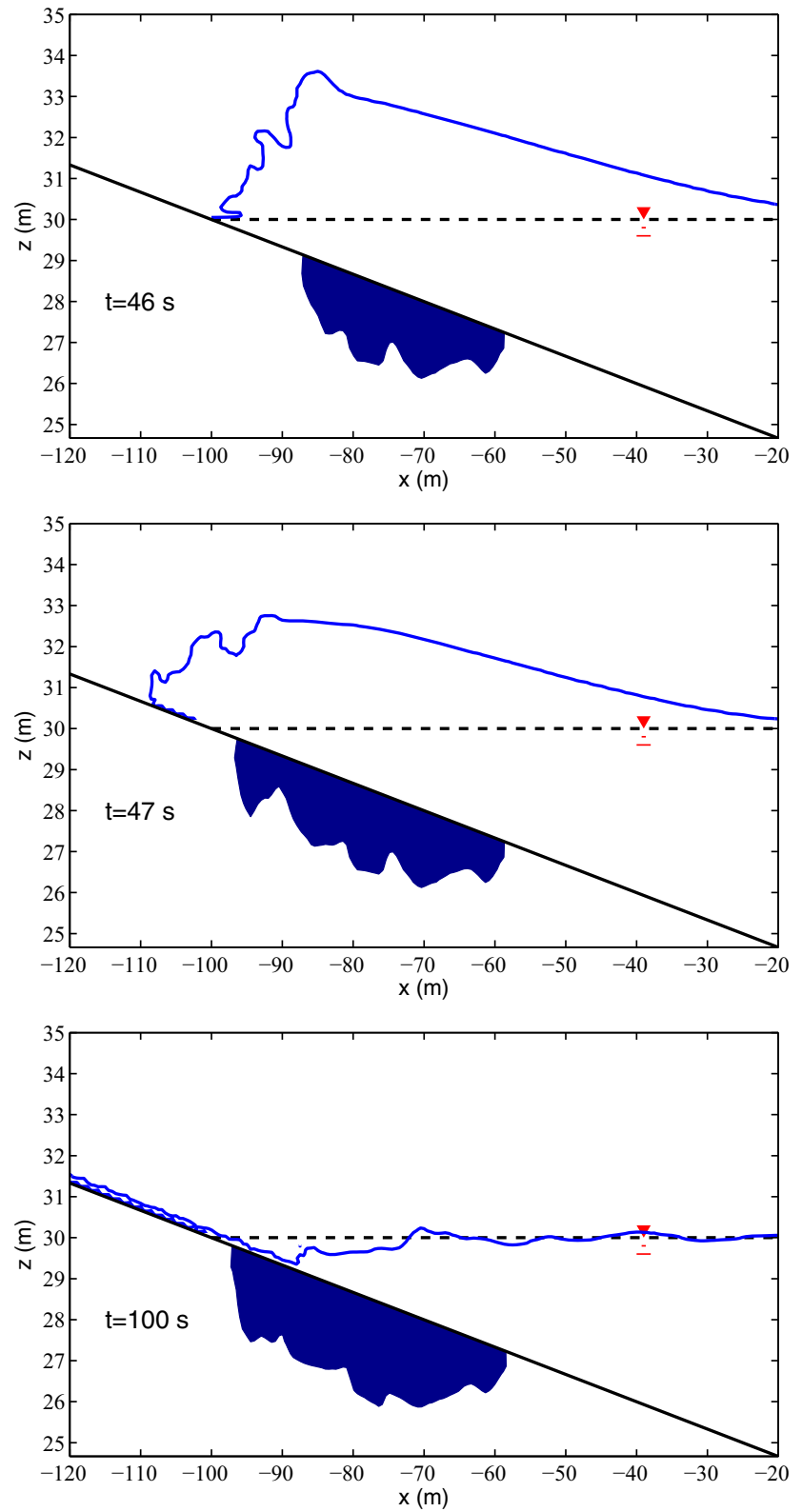

(b) 1:15 slope

Fig. 11 Development of liquefaction zone versus time for 1:6 and 1:15 slope

the coordinate is close to the slope and far away from the hydraulic jump for both cases. Due to the fact that a steeper slope accompanies with a faster rate of wave loading and unloading, the peak negative pore pressure is greater for the 1:6 slope as well. The oscillatory pore pressure increases significantly at $t \approx 30 \mathrm{~s}$ for 1:6 case and $t \approx 50 \mathrm{~s}$ for $1: 15$ case accompanies with an instantaneous rise in the pore pressure accumulation due to the sudden increase in overburden stress induced by arrival of wave. There exists some energy dissipation induced by the interaction between wave and seabed when wave begins running up over the slope, during which both the oscillatory and residual pore pressures begin to dissipate. An increase in the upward seepage force occurs between $50 \mathrm{~s}<t<65 \mathrm{~s}$ for 1:6 case and $80 \mathrm{~s}<t<120 \mathrm{~s}$ for 1:15 case, which is induced by the drawdown wave. The oscillatory liquefaction is more likely to happen during this period due to upward vertical pore pressure gradients as discussed by Young et al. (2009). The residual pore pressure will build up again during this period, after which the residual pore pressures gradually decrease, followed by a progressive dissipation in the wave-induced oscillatory pore pressures. 


\subsection{Development of liquefaction zone}

In general, the definition for liquefaction is based on the following three categories: excess pore pressure-based criterion, strength-based criterion, and shear deformation-based criterion. The shear deformation-based criterion suggests that there exists a threshold of shear strain, above which the soil could have been liquefied. Due to the fact that the threshold of shear deformation for different soil in liquefied status is significantly different, the application of the shear deformation-based criterion is limited. The strengthbased criterion is based on the assumption that the liquefied soils cannot regain strength when the effective contact stress becomes zero. Basically, the excess pore pressure-based criterion is an extension based on the strength-based criterion as it assumes that the soil would be liquefied when the excess pore pressure becomes equal to the initial vertical effective overburden stress. Regarding the residual liquefaction induced by the build-up of residual pore pressure in this study, we assume that the soil is liquefied when $\bar{p} / \sigma_{0}^{\prime}=1$ based on the excess pore pressure-based criterion. The development of liquefaction zone for the 1:6 and 1:15 slopes is shown in Fig. 11. It can be observed from Fig. 11 that liquefaction occurs in the near shore region below the initial shoreline, when wave passes through the sloping seabed. The residual pore pressure builds up immediately as the result of the significant shear strains caused by arrival of the waves. The build-up of residual pore pressure may overcome the overburdened weight of the soil leading to the residual liquefaction when the dissipation of pore pressure is impeded in densely packed soil at the vicinity or below SWL. Then, this liquefied region can spread laterally and vertically to the neighboring points as the wave propagating over the slope. As discussed previously, the pore pressure within the soil can build up again in the region which is close to the hydraulic jump during the drawdown phase. As a result, the liquefaction zone will eventually be extended to the region around the hydraulic jump. Figure 11 illustrates that the area of the liquefaction zone is dependent on the gradient of the slope. The depth of the liquefaction zone increases and the width of the liquefaction zone decreases as the gradient of bed slope increases.

\subsection{Parametric studies of wave-induced pore pressure accumulation}

Wave height will directly affect wave energy and wave forces acting on the marine sediments; thus it is important to examine the influence of wave height on the pore pressure accumulation during the wave run-up and drawdown. However, as discussed in Xiao et al. (2010), larger wave with the same initial water depth over a mild slope is more likely to break resulting in a decrease in wave height prior to reaching the near-shore region; therefore, the effect of

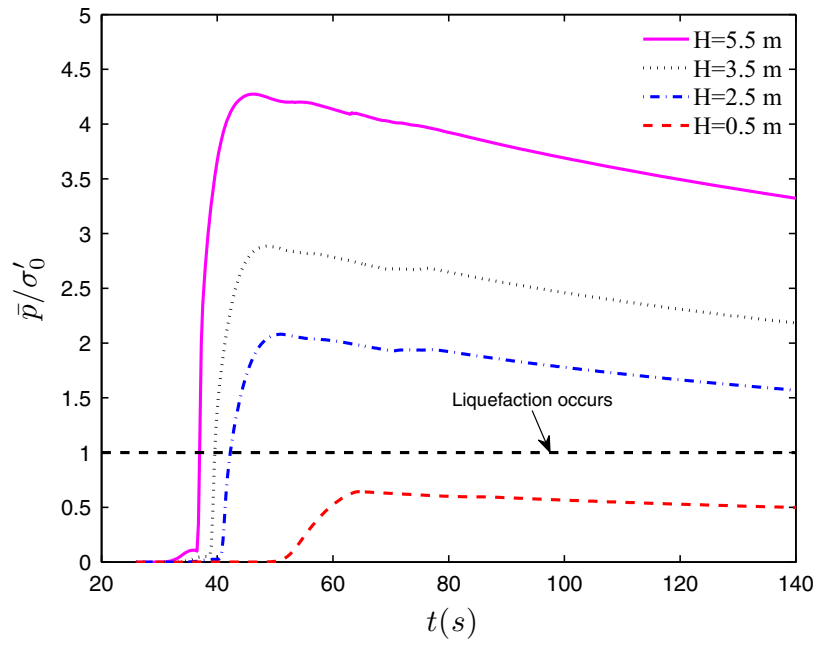

Fig. 12 The effect of wave height $(H)$ on the wave-induced build-up of residual pore pressure with increasing time at $(x, z)=(-10,-1) \mathrm{m}$

wave heights on this occasion may not be obvious. Since there is no obvious wave breaking for the case with a 1:6 slope, the wave heights varying from 5.5 to $0.5 \mathrm{~m}$ over the same initial water depth $(d=10 \mathrm{~m})$ propagating over a $1: 6$ slope are considered in this study. The soil properties in this study are selected as follows: relative density $\left(D_{r}\right)=0.2$; permeability $\left(k_{s}\right)=10^{-6} \mathrm{~m} / \mathrm{s}$. The location in this analysis is selected at $(x, z)=(-10,-1) \mathrm{m}$ just below the initial shoreline, which is far away from the hydraulic jump location. Figure 12 illustrates the distribution of pore pressure accumulation versus time for four different wave heights. An instantaneous increase in the pore pressure accumulation is observed when wave arriving at the slope, after which it begins to dissipate progressively due to the dissipation in wave energy induced by the wave-seabed interaction. It will take longer for smaller amplitude wave to build up to reach the line that is the criterion of residual liquefaction. When the wave height drops down below $0.5 \mathrm{~m}$, it is unlikely for the seabed in this location to be liquefied. It should be noted that the present model can only capture the build-up of pore water pressure up to the occurrence of liquefaction $\left(\bar{p} / \sigma_{0}^{\prime}=1\right)$. Regarding the prediction for liquefied soil with an entirely different constitutive behavior, a more sophisticated model (Sassa et al. 2001) incorporating post-liquefaction processes is required.

Besides the wave characteristics, soil properties are also important for the wave-induced pore pressures in marine sediments. In this section, we examine two important soil parameters, relative density $\left(D_{r}\right)$ and permeability $\left(k_{S}\right)$. The wave height is selected as $5.5 \mathrm{~m}$ over $10 \mathrm{~m}$ initial water depth. The configuration of the slope is the same as what has been discussed previously. Figure 13 illustrates the effect of permeability $\left(k_{s}\right)$ and relative density $\left(D_{r}\right)$ on the time variation of pore pressure accumulation at $(x, z)=(-10,-1) \mathrm{m}$. As 


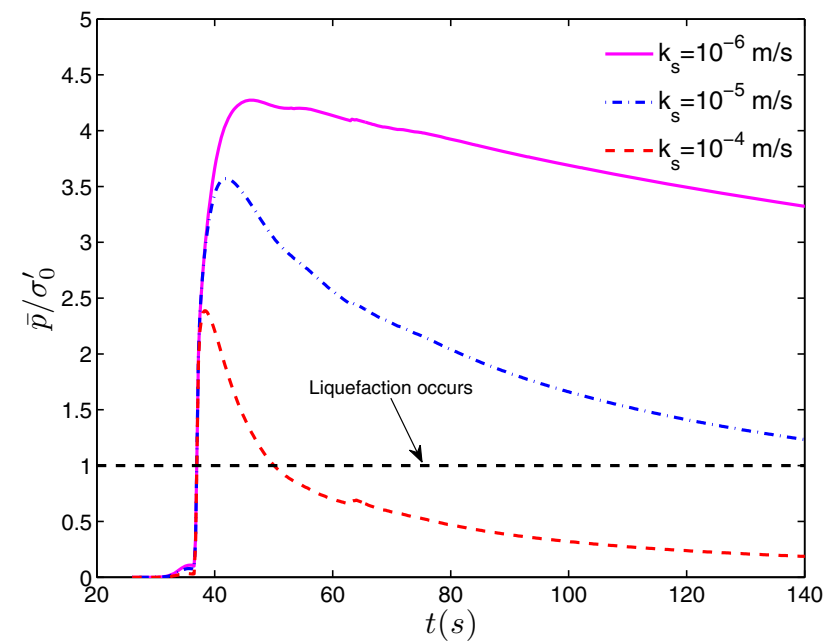

(a) Various permeability $\left(k_{s}\right)$

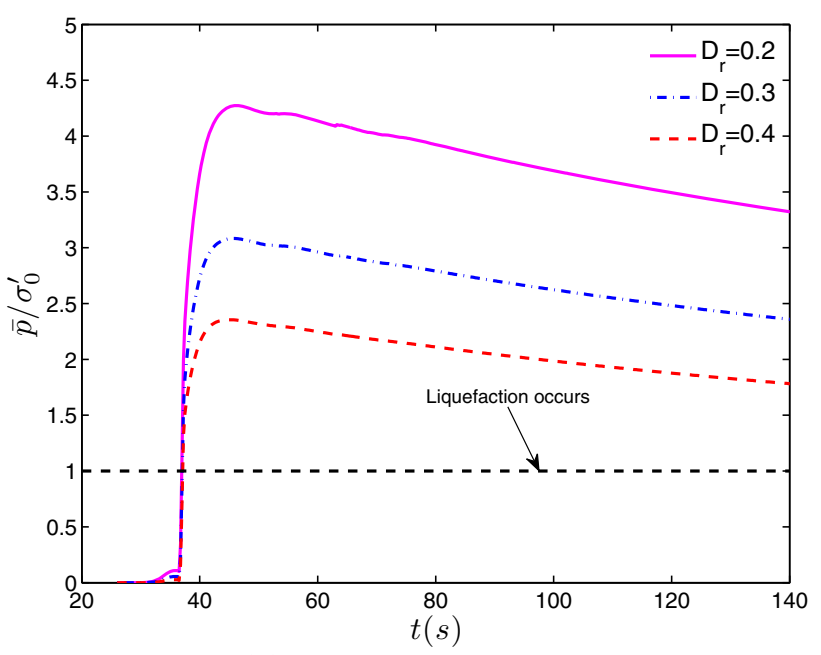

(b) various relative density $\left(D_{r}\right)$

Fig. 13 The effects of permeability $\left(k_{s}\right)$ and relative density $\left(D_{r}\right)$ on the wave-induced build-up of residual pore pressure with increasing time at $(x, z)=(-10,-1) \mathrm{m}$

shown in the figure, the pore pressure can accumulate to a larger value in the foundation with low soil permeability and relative density. It is also observed that the pore pressure dissipates very quickly with a high permeability, because the energy and pore pressure are more difficult to drain out in the soil with a low permeability.

Where liquefaction occurs and how the maximum liquefaction depth is are the most important tasks for engineers involved in the design of coastal infrastructures in a region susceptible to liquefaction. In this study, we use the parameter $\left(L_{m}\right)$ to define the maximum liquefaction, which is the maximum vertical distance when the maximum liquefaction region occurs. Figure 14 demonstrates the effect of soil properties and wave heights on the maximum liquefied depth. In the example, the wave heights $(H)$ vary from 0.5 to $5.5 \mathrm{~m}$, while the seabed permeability $\left(k_{s}\right)$ and relative density $\left(D_{r}\right)$
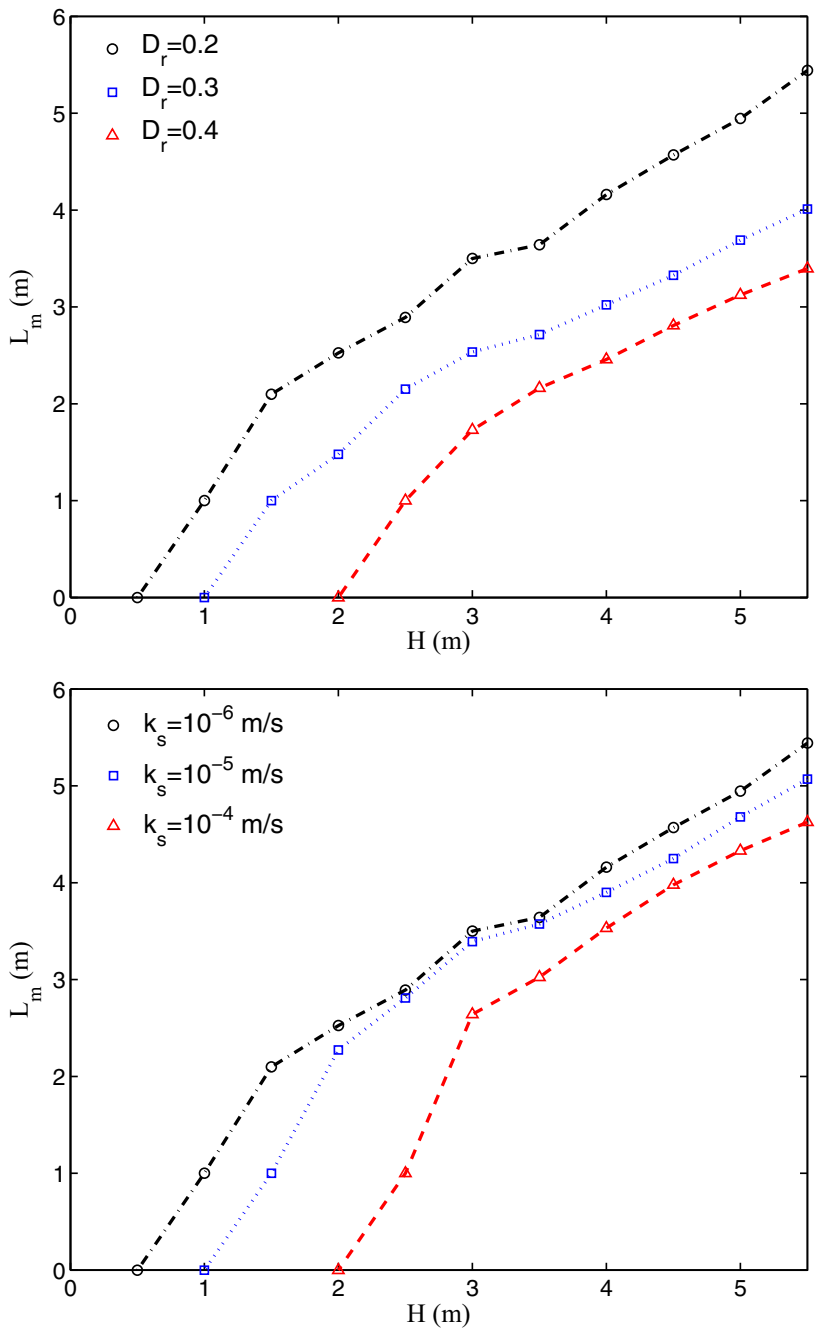

Fig. 14 Distribution of maximum liquefaction depth

range from $10^{-6}$ to $10^{-4} \mathrm{~m} / \mathrm{s}$ and 0.2 to 0.4 , respectively. As illustrated in Fig. 14, the maximum liquefaction depth $\left(L_{m}\right)$ increases as the permeability and relative density increase. It is also observed that wave height significantly affects the wave-induced maximum liquefaction depth. The maximum liquefaction depth basically has positive correlation with the wave amplitude.

\section{Conclusions}

In this study, we develop an integrated model to investigate the potential for residual liquefaction in coastal sandy slopes subject to solitary wave loading. Based on the numerical results presented, the following conclusions can be drawn:

(1) The initial consolidation state for a sloping seabed under static water pressure is much different from that for a flat seabed foundation. This initial consolidation state 
should be determined first, then is taken as the initial condition for the followed dynamic analysis.

(2) The wave motions are significantly affected by the gradient of the slope seabed foundation. Numerical results indicated that the complete sequence of the solitary wave propagation over a 1:15 slope involves the following processes: shoaling, wave breaking; run-up; drawdown; hydraulic jump; and trailing wave. Compared to the 1:15 case, no obvious wave shoaling as well as wave breaking occurs for a steep 1:6 slope. It is also observed that the duration of wave runup and rundown over a 1:15 is longer than that in a steep 1:6 slope.

(3) The wave-induced shear stress and pore pressure increase instantaneously when the wave arriving at the slope. Then both of them begin to dissipate due to the energy dissipation induced by the wave-seabed interaction. An increase in the magnitudes of negative pore pressures is observed during the hydraulic jump phase, during which the residual pore pressure will increase again due to the increase of wave-induced shear strains. Furthermore, the peak value of pore pressures and shear stress for a 1:6 slope are greater than that for a 1:15.

(4) The distribution of wave-induced pore pressure in the $\mathrm{x}$-direction between the hydraulic jump location and water-seabed intersection are significantly different for both cases of 1:6 slope and 1:15 slope. This is mainly because that no breaking wave occurs in the case of 1:6 slope, while breaking wave occurs in the case of 1:15 slope.

(5) The seabed in the region below the initial shore line along the seabed surface is liquefied first when the wave passes through the sloping seabed. Then this liquefied region can be extended laterally and vertically to the neighboring points, and eventually to the region around the hydraulic jump. Moreover, the width of the liquefaction zone increases and the depth of liquefaction zone decreases as the bed slope decreases.

(6) The wave-induced residual pore pressure builds up faster and can accumulate to a large value in the case of soil with lower permeability and relative density subject to large amplitude wave loading.

Unlike ocean waves by wind, a solitary wave does not yield cyclic shear stress and induces a type of monotonic shearing with a stress reversal. However, theoretical part in this study for determining the build-up of residual pore pressure is based on the assumption that the soil is undergoing cyclic shearing. Hence, the predictions shown and discussed with respect to the accumulation of residual pore pressure during a solitary wave run-up and drawdown in this paper remain hypothetical. More sophisticated model such as constitutive elasto-plastic model with physical validation regarding the residual pore pressure under a solitary wave is required in the future.
Acknowledgments The authors gratefully acknowledge the support of the Griffith University eResearch Service team and the use of the High Performance Computing Cluster, Gowonda, to complete this research. The first author is thankful for the support of Griffith University Deputy Vice Chancellor (Research) International Postgraduate Scholarship and SEET Postgraduate Research Scholarship.

\section{References}

Bierawski LG, Maeno S (2004) Vof-fem numerical model of submerged breakwater on permeable bottom. J Appl Mech JSCE 7:945-952

Biot MA (1941) General theory of three-dimensional consolidation. J Appl Phys 26(2):155-164

Hsu JRC, Jeng DS (1994) Wave-induced soil response in an unsaturated anisotropic seabed of finite thickness. Int J Numer Anal Methods Geomech 18(11):785-807

Hsu TJ, Sakakiyama T, Liu PLF (2002) A numerical model for wave motions and turbulence flows in front of a composite breakwater. Coast Eng 46:25-50

Jeng DS (2013) Porous models for wave-seabed interactions. Springer, Heidelberg

Jeng DS, Zhang H (2005) An integrated three-dimensional model for wave-induced pore pressure and effective stresses in a porous seabed. ii: breaking waves. Ocean Eng 32(16):1950-1967

Jeng DS, Zhao HY (2014) Two-dimensional model for accumulation of pore pressure in marine sediments. J Waterway Port Coast Ocean Eng ASCE 141(3):04014,042

Jeng DS, Ye JH, Zhang JS, Liu PLF (2013) An integrated model for the wave-induced seabed response around marine structures: model verifications and applications. Coast Eng 72:1-19

Lin P, Liu PLF (1999) Internal wave-maker for Navier-Stokes equations models. J Waterway Port Coast Ocean Eng ASCE 125(4):207-215

Liu PLF, Lin P, Chang KA, Sakakiyama T (1999) Numerical modelling of wave interaction with porous structures. J Waterway Port Coast Ocean Eng ASCE 125(6):322-330

Madsen OS (1978) Wave-induced pore pressures and effective stresses in a porous bed. Géotechnique 28(4):377-393

McDougal WG, Tsai YT, Liu PLF, Clukey EC (1989) Wave-induced pore water pressure accumulation in marine soils. J Offshore Mech Arct Eng ASME 111(1):1-11

Nago H, Maeno S, Matsumoto T, Hachiman Y (1993) Liquefaction and densification of loosely deposited sand bed under water pressure variation. In: Proceeding of the 3rd international offshore and polar engineering conference, Singapore, vol I, pp 578-584

Rodi W (1993) Turbulence models and their application in hydraulicsstate-of-the-art review, 3rd edn. Balkema, Rotterdam

Sassa S, Sekiguchi H (1999) Wave-induced liquefaction of beds of sand in a centrifuge. Géotechnique 49(5):621-638

Sassa S, Sekiguchi H (2001) Analysis of wave-induced liquefaction of sand beds. Géotechnique 51(2):115-126

Sassa S, Sekiguchi H, Miyamamot J (2001) Analysis of progressive liquefaction as a moving-boundary problem. Géotechnique 51(10):847-857

Seed HB, Rahman MS (1978) Wave-induced pore pressure in relation to ocean floor stability of cohesionless soils. Mar Geotechnol 3(2): $123-150$

Sekiguchi H, Kita K, Okamoto O (1995) Response of poro-elastoplastic beds to standing waves. Soils Found 35(3):31-42

Sumer BM (2014) Liquefaction around marine structures. World Scientific, $\mathrm{NJ}$

Sumer BM, Fredsøe J (2002) The mechanism of scour in the marine environment. World Scientific, NJ 
Sumer BM, Sen MB, Karagali I, Ceren B, Fredsøe J, Sottile M, Zilioli L, Fuhrman DR (2011) Flow and sediment transport induced by a plunging solitary wave. J Geophys Res 116(C01):008

Sumer BM, Kirca VSO, Fredsøe J (2012) Experimental validation of a mathematical model for seabed liquefaction under waves. International J Offshore Polar Eng 22:133-141

Synolakis CE (1987) The runup of solitary waves. J Fluid Mech 185:523-545

Ulker MBC, Rahman MS, Jeng DS (2009) Wave-induced response of seabed: Various formulations and their applicability. Appl Ocean Res 31(1):12-24

Xiao H, Young YL, Prévost JH (2010) Parametric study of breaking solitary wave induced liquefaction of coastal sandy slopes. Ocean Eng 37:1546-1553

Ye J, Jeng DS (2012) Response of seabed to natural loading-waves and currents. J Eng Mech ASCE 138(6):601-613

Ye J, Jeng DS, Wang R, Zhu C (2013) Numerical study of the stability of breakwater built on a slope porous seabed under tsunami loading. Appl Math Modell 37(23):9575-9590
Ye J, Jeng DS, Liu PF, Chan AHC, Wang R, Zhu C (2014) Breaking wave-induced response of composite breakwater and liquefaction in seabed foundation. Coast Eng 85:72-86

Young YL, White JA, Xiao H (2009) Liquefaction potential of coastal slopes induced by solitary waves. Acta Geotech 4:17-34

Zen K, Yamazaki H (1990) Oscillatory pore pressure and liquefaction in seabed induced by ocean waves. Soils Found 30(4):147-161

Zhang H, Jeng DS (2005) An integrated three-dimensional model for wave-induced pore pressure and effective stresses in a porous seabed. i: a sloping seabed. Ocean Eng 32(5-6):701-729

Zhao HY, Jeng DS (2015) Numerical study of wave-induced soil response in a sloping seabed in the vicinity of a breakwater. Appl Ocean Res 51:204-221

Zhao HY, Jeng DS, Guo Z, Zhang JS (2014) Two dimensional model for pore pressure accumulations in the vicinity of a buried pipeline. $\mathrm{J}$ Offshore Mech Arct Eng ASME 136(4):042,001 